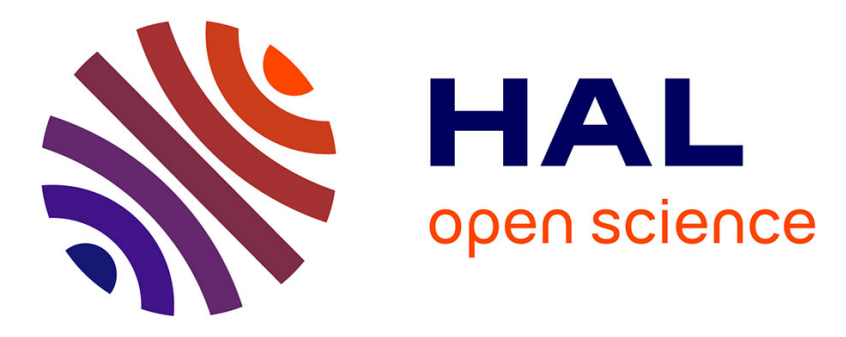

\title{
Patients Lung Derived Tumoroids (PLDTs) to model therapeutic response
}

Frederic Delom, Inaki Begiristain, Thomas Grenier, Hugues Begueret, Fabienne Soulet, Géraldine Siegfried, Abdel-Majid Khatib, Jacques Robert, Delphine Fessart

\section{To cite this version:}

Frederic Delom, Inaki Begiristain, Thomas Grenier, Hugues Begueret, Fabienne Soulet, et al.. Patients Lung Derived Tumoroids (PLDTs) to model therapeutic response. Biochimica et Biophysica Acta Molecular Cell Research, 2020, 1867 (11), pp.118808. 10.1016/j.bbamcr.2020.118808 . hal-02931566

\section{HAL Id: hal-02931566 https://hal.science/hal-02931566}

Submitted on 15 Sep 2020

HAL is a multi-disciplinary open access archive for the deposit and dissemination of scientific research documents, whether they are published or not. The documents may come from teaching and research institutions in France or abroad, or from public or private research centers.
L'archive ouverte pluridisciplinaire HAL, est destinée au dépôt et à la diffusion de documents scientifiques de niveau recherche, publiés ou non, émanant des établissements d'enseignement et de recherche français ou étrangers, des laboratoires publics ou privés. 


\section{Patients Lung Derived Tumoroids (PLDTs) to model therapeutic response}

Frederic Delom ${ }^{3 *}$, Inaki Begiristain ${ }^{3 \ddagger}$, Thomas Grenier ${ }^{3 \ddagger}$, Hugues Begueret ${ }^{3,4}$, Fabienne Soulet ${ }^{5,6}$, Geraldine Siegfried $^{5,6}$, Abdel-Majid Khatib ${ }^{5,6}$, Jacques Robert ${ }^{3}$ and Delphine Fessart ${ }^{1,2,3 *}$

${ }^{1}$ INSERM U1242, "Chemistry, Oncogenesis Stress Signaling”, Univ. R $\cdot r$ nes 1, F-35000 Rennes, France; ${ }^{2}$ Centre de Lutte Contre le Cancer Eugène Marquis, F-35000 Rer،ı_. France; ${ }^{3}$ ARTiSt Group, Univ. Bordeaux, INSERM, Institut Bergonié, ACTION, U1218, F-330کð surdeaux, France; ${ }^{4}$ Hôpital HautLévêque, CHU de Bordeaux, avenue de Magellan, 3360^ Pesudc cedex, France. ${ }^{5}$ Université de Bordeaux, Bordeaux, France ; ${ }^{6}$ INSERM UMR1029, 33400. Pes: $7 c$, France.

${ }^{\ddagger}$ Equally contributed

*Correspondence to:

DF - E-mail: delphine.fessart@inserm.fr c.FD - E-mail: frederic.delom@yahoo.fr

Key words: Tumoroids, Three-dimı nsional culture, Radiation, Chemotherapeutic drugs, Lung cancer. 


\section{Abstract}

Preclinical lung cancer models are essential for a basic understanding of lung cancer biology and its translation into efficient treatment options for affected patients. Lung cancer cell lines and xenografts derived directly from human lung tumors have proven highly valuable in fundamental oncology research and anticancer drug discovery. Both models inherently comprise advantages and caveats that have to be accounted for. Recently, we have enabled reliable in vitro culture techniques from lung cancer biopsies as Patients Lung Derived Tumoroids (PLDTs). This breakthrough provides the possibility of high-throughput drug screening covering the spertrum of lung cancer phenotypes seen clinically. We have adapted and optimized our in vitro three-Nime. cional model as a preclinical lung cancer model to recapitulate the tumor microenvironment ${ }^{-{ }^{N} M^{\prime}}$-) using matrix reconstitution. Hence, we developed directly PLDTs to screen for chemothera, rel'.ics and radiation treatment. This original model will enable precision medicine to become $\ldots$. be screened for effective ex vivo therapeutics, aiming a railoring of treatments specific to that individual. Hence, this tool can enhance clinical o itr smes and avoid morbidity due to ineffective therapies. 


\section{Introduction}

Lung cancer is the most common cause of cancer-related mortality worldwide. Of lung cancer diagnosed, more than $80 \%$ are non small cell lung cancer (NSCLC), which includes adenocarcinoma, squamous cell carcinoma and large cell carcinoma [1]. The most common histological subtype of lung cancer is adenocarcinoma, accounting for almost half of all cancers $[2,3]$. The majority of NSCLC patients are diagnosed during the later stages of lung cancer and dies without successful treatment $[1,4,5]$

One of the most difficulties in lung oncology is to develop a reliable model to assess the potential effects of candidate drugs. Preclinical research on anticar cer drugs has the lowest success rate of all therapeutic areas, with 5\% of candidate compounds ruving completed Phase III clinical

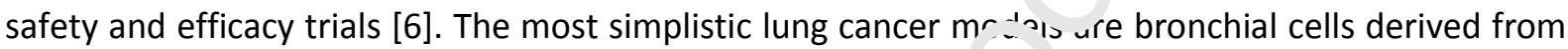
human and animal lung tumors grown as a flat monolayer $n$ c:" culture media. There is no doubt that immortalized lung tumor lines grown in 2D have con ribc ted to a great deal of knowledge about the mechanisms leading to cancer development. Hov evt: in this monolayer model, lung cells adhere to an artificial substrate and are in contact wih other cells only at the periphery. Thus lung cells cultured in flat layers on plastic surfa a not reflect the multicellular microenvironment found in the bronchial tree. Animal models 1 . ve been used as live incubators in which human lung tumors have been cultured, thus interacing with an entire organism, though often in an immunedepressed environment. Lung cance s $\mathrm{h}$. ve been established in rodent models by surgically implanting pulmonary tumor cells or $\mathrm{b}$; creating genetically modified animals that spontaneously develop human lung tumors in res, onse to experimental modification of the expression of a specific gene. At first glance, this set.ns in inherently desirable system aiming at mimicking human lung cancer. Despite their inte ssivf use for drug screening, these expensive animal models have not resulted in therapies transli ting into better outcomes of human cancer $[7,8]$. Overall, these models have not generated therapies with a high return on investment.

For their fascinating potential as tools to probe human biology and disease, the journal Nature Methods has chosen organoids as "method of the year" in 2018 [9]. One of the most powerful aspects of organoids as research tools is how they have moved forward our understanding of human cancer biology. We have previously developed a 3D organoids/tumoroids tissue culture model from normal and malignant human lung epithelial cells [10]. Indeed, we have enabled a reliable in vitro model from lung cancer biopsies as Patient-Lung Derived Tumoroids (PLDTs) [10] to establish novel personalized lung cancer therapies. These therapies could define specific treatments for each patient on an individual basis. Using this method, we have characterized 
organoids/tumoroids and showed that epithelial organization and many physiological cell-cell and cell-ECM contacts, cellular polarity, and secretory functions are preserved in epithelial organoids [10, 11]. Therefore, the tumoroids, in which cellular heterogeneity of tumor cells is preserved, have emerged as a promising tool. Recently, numerous studies highlighted the application of patientderived tumoroids in personalized cancer medicine in terms of gene - drug association treatments, the identification of new therapies and the prediction of patient response. Thus using PLDT with similar characteristics to the original lung tumors may result in more accurate predictions of drug responses in patients. PLDTs have several advantages over pre-existing models, including conserving the molecular and cellular composition of the original tumor [12]. These advantages highlight the tremendous potential of PLDTs in personalized lung cancer therc ${ }^{*} \cdot v$, particularly preclinical drug screening and predicting patient responses to selected treatment 'egIı 'ens.

In the present study, we have adapted and optimi ${ }_{2}$ 'd ' ur in vitro 3D model [10] as a potential personalized lung cancer medicine model. Persr.../l< $\mathbf{d}$ cancer medicine is an approach to tailoring effective therapeutics strategies for each $w^{\text {t:ent }}$ according to a tumor genomic characterization. We have investigated the utilit $\mathrm{c}$. our PLDT model in testing the activity of chemotherapeutic drugs alone or in combinatior, vith irradiation by comparing 2D vs 3D cultures of the same lung cancer cells obtained from hic ssies of lung cancer patients. Herein, we show that PLDTs are more resistant to chemothe, neutic drugs and irradiation that cells in 2D culture. Thus, the PLDT model could enable precision $n$. virıne to become a reality, allowing patients samples to be screened for effective therapy, with wn talloring of treatments specific to each individual. Hence, this tool can enhance clinical outcom: 's by developing and delivering the right therapeutics, for the right cancer in the right patients. This $w$. uld mean that outcome, morbidity, and ultimately survival should be improved for all patient; $W_{1}, 4$ advanced lung cancer. 


\section{Materials and methods}

\subsection{Cell isolation and cell lines culture}

Cancer lung epithelial cells obtained from tumor biopsies of patients were cultured in two different culture media: medium A containing $5 \mathrm{ng} / \mathrm{ml}$ epidermal growth factor (EGF), $50 \mu \mathrm{g} / \mathrm{ml}$ bovine pituitary extract (BPE) and 1\% antibiotics mixt (100 IU/ml penicillin and $100 \mu \mathrm{g} / \mathrm{ml}$ streptomycin); and medium B supplemented with $15 \mu \mathrm{g} / \mathrm{ml} \mathrm{BPE}, 10 \mathrm{ng} / \mathrm{ml} \mathrm{EGF,} 0.5 \mu \mathrm{g} / \mathrm{ml}$ epinephrine, $5 \mu \mathrm{g} / \mathrm{ml}$ insulin, $10 \mu \mathrm{g} / \mathrm{ml}$ transferrin, $10 \mathrm{ng} / \mathrm{ml}$ triiodo-L-thyronine, $0.5 \mu \mathrm{g} / \mathrm{ml}$ hydrocortisone, $1.5 \mu \mathrm{g} / \mathrm{ml}$ albumin, 0.1 $\mathrm{ng} / \mathrm{ml}$ retinoic acid, 1\% Fetal Calf Serum (FCS) and 1\% antibiotics mixt (100 IU/ml penicillin and 100 $\mu \mathrm{g} / \mathrm{ml}$ streptomycin).

Samples of human lung cancer tissues were obtained from the Hau :-Levêque University Hospital (Bordeaux, France) and reviewed by an expert pathologist ir the field (H. Begueret) as previously published in [11]. These procedures were approved by thi Institutional Review Board at HautLevêque University Hospital (NFS96900 Certification) in . rco dance with The Code of Ethics of the World Medical Association. Immediately after sur-i:al resection, tumor biopsies were rinsed in Hank's Balanced Salt Solution (PAN Biotech) and (ut $\ldots:-2-3 \mathrm{~mm}$ pieces. For the explant culture, these pieces are placed in a 6-well plate, previous' $\checkmark$ cc tted with a solution containing $30 \mu \mathrm{g} / \mathrm{ml}$ collagen, 10 $\mu \mathrm{g} / \mathrm{ml}$ fibronectin and $10 \mu \mathrm{g} / \mathrm{ml}$ BSA. The exp.ant was covered with a drop of culture medium (medium $\mathrm{A}$ or $\mathrm{B}$ ) and incubated at $37^{\circ} \mathrm{C}, 5 \% \mathrm{CO}_{2}$. Then $2 \mathrm{ml}$ of culture medium $\mathrm{A}$ or $\mathrm{B}$ was added to the explant. The culture medium w- $c_{1}-$.lged every 2 days. When the cells were confluent, they were detached from the plate wit i tr,, sin and seeded in 12-well plates.

For the enzymatic digestion, $\mathrm{i}$-sur $\mathrm{S}$ from biopsies were rinsed in HBSS and cut into 2-3 $\mathrm{mm}$ pieces before being minced and $\mathrm{i}$. cub ted for 1 to 2 hours at $37^{\circ} \mathrm{C}$ in DMEM alone containing 50 to $1500 \mu \mathrm{l}$ of collagenase I (Worthing )n). After digestion, the supernatant was recovered gently and filtered through a $40 \mu \mathrm{m}$ filter. The samples were then centrifuged for $7 \mathrm{~min}$ at $4^{\circ} \mathrm{C}$ at $250 \mathrm{~g}$. The pellet was taken up twice in DMEM alone and was centrifuged for 5 min at $4^{\circ} \mathrm{C}$ at $250 \mathrm{~g}$. Finally, cells were taken up in culture medium A and seeded in a 6-well plate. Once the cells adhered to the support, the medium was changed every 2 days.

Two human cell lines were used: human fetal lung fibroblasts (IMR-90) and human embryonic kidney cells (HEK293). HEK293 were cultured in DMEM medium supplemented with $10 \%$ FBS and $1 \%$ antibiotics (100 IU/ml penicillin and $100 \mu \mathrm{g} / \mathrm{ml}$ streptomycin). The IMR-90 cells were cultured in Eagle MEM medium supplemented with $10 \%$ FBS, $1 \%$ L-glutamine and $1 \%$ antibiotics $(100 \mathrm{IU} / \mathrm{ml}$ 
penicillin and $100 \mu \mathrm{g} / \mathrm{ml}$ streptomycin). All cultures were kept in a humid incubator at $37^{\circ} \mathrm{C}$ and $5 \%$ $\mathrm{CO}_{2}$. Sub-culturing was performed when the cells were $80 \%$ confluent.

\subsection{Chemotherapeutic assay in $2 D$ monolayers}

Cells were seeded in triplicate at 5000 cells $/ \mathrm{mL}$ in a 96 -well plate and incubated at $37^{\circ} \mathrm{C}$ and $5 \% \mathrm{CO}_{2}$. Four days after seeding, cells were treated with concentrations of $0 ; 0.01 ; 0.1 ; 1 ; 10$ and $100 \mu \mathrm{M}$ of Docetaxel, Paclitaxel, Pemetrexed and Gemcitabine. To perform this treatment, 50\% of the medium was replaced by complete DMEM medium supplemented with the chemotherapeutic agent. In parallel, untreated cellular control was performed. Three and five days after starting treatment, the cytotoxic effect of the four chemotherapeutic agents was me-ured by a cell viability assay (AlamarBlue). Briefly, AlamarBlue ${ }^{\circledR}$ solution was added to each we $1,1 \%$ of the final volume, and the plate was incubated at $37^{\circ} \mathrm{C}$, in the dark for 2 hours. After in un tion, the absorbance was read at 570 and $600 \mathrm{~nm}$ using a spectrophotometer. The reduction $\uparrow$ rcentrage of AlamarBlue, corresponding to cell viability, was determined according to manufactur $r$ ins 'ructions.

\subsection{Measuring response to Gemcitabine in soft-agar jo Jny formation}

Colony formation efficiency was evaluated i $p$ evı usly described [11]. Briefly, cells were plated in medium supplemented with $3.3 \%$ FBS contaı : ing $0.35 \%$ soft agar in 6 -wells plates over a layer of solidified medium containing $0.7 \%$ soft c.rar. Four days after seeding, cells were treated with concentrations of $0 ; 0.01 ; 0.1 ; 1 ; 10$ an $1100 \mu \mathrm{M}$ of Gemcitabine. The medium was replaced with fresh Gemcitabine twice a week « maıntain humidity. After growth, colonies were stained with Crystal Violet $(0.05 \%)$ for $10 \mathrm{mi}$ ar, counted using a phase-contrast microscope (Leica) at objective $5 \times$. The acquisition of images $: n d$ their analysis were performed with the Leica software of the microscope (LAS X Softr. $7 r_{t}$, If.ca).

\subsection{Measuring response to Gemcitabine in $3 D$}

Cells were grown in 3D tumoroids according to our protocol $[10,11]$. Briefly, the cells were seeded in a Matrigel matrix at the density of 2000 cells $/ \mathrm{cm}^{2}$ in a 96 -well plate and incubated at $37^{\circ} \mathrm{C}$ and $5 \%$ $\mathrm{CO}_{2}$. Treatment with chemotherapeutic agents began 4 days after seeding and was repeated at 7,9 days. For each treatment, tumoroids were treated with concentrations of $0 ; 0.01 ; 0.1 ; 1 ; 10$ and 100 $\mu \mathrm{M}$ Gemcitabine. For this purpose, $50 \%$ of the medium was replaced by a complete DMEM medium supplemented with the chemotherapeutic agent. In parallel, cellular control was performed with the vehicle. To calculate the number of tumoroids, a representative field in each condition was taken using a phase contrast-microscope (Leica) at objective $5 \times$. The acquisition of a Z-stack (15 images) of each well and its analysis was performed with the Leica software of the microscope (LAS Software, 
Leica). Briefly, for each multifocal image obtained with a Z-stack, we have applied a step-by-step analysis workflow containing 11 steps to obtain the organoid count and a size-wise classification. First, we selected the multifocal image, next we applied filters with gray processing followed by an enhancement of black objects set up to 14. The threshold was then adjusted to reduce the background noise. The image was then converted to binary processing for tumoroid detection. Once the new binary image was obtained, we have controlled that each tumoroid was recognized. We have then processed to the measurement of each tumoroid, and defined each tumoroid as an object, to automatically calculate the diameter and the number of each object. Afterward, we have classified the objects by size using 10 classes from the smaller tumoroid to the biggest one. Finally, we have obtained a histogram with the number of tumoroid per field and the "iameter of tumoroids.

\subsection{Cell death assay}

Cells were seeded into a 96-well plate and grown for 4 da $;$ in $\angle \nu$ and 3D. After 4 days, cells were treated with different doses of Gemcitabine for 3 day Ce 's were then stained for 30 min with NucBlue Live ReadyProbes Reagent (1 drop/ml meda) aı.d NucGreen Dead 488 ReadyProbes Reagent ( $1 \mathrm{drop} / \mathrm{ml}$ media) (ThermoFisher). The $96-$ "sll , late was imaged immediately. High-content images were acquired with the Cytation $3=\mathrm{stc}$ nal d microscope (Biotek) at $4 \times$ magnification, and analysis was performed using the Analysis sotı ' 'are (Biotek). Cells were imaged simultaneously in the fluorescein isothiocyanate (FITC) (NucGre`n) and 4', 6-diamidino-2-phenylindole (DAPI) (NucBlue) channels. A cell was defined as undergo ng cell death when $50 \%$ or more of the nucleus, as defined by NucBlue-positive pixels, was ove. 'əpped by NucGreen-positive pixels.

\subsection{Chemoradiation in vitro st'וdies}

Cells were seeded in $9 i$ ' $w t^{\prime \prime}$ fr imat using a Perkin-Elmer Janus Mini liquid handling platform. Plates were incubated for the ind cated times, and the medium was changed every two days. Tumoroids were plated in 96-well plates and allowed to grow for 1 day. Images were taken on a Leica DMi8 inverted microscope using a $4 \times$ objective before chemoradiation treatment. After imaging of monolayer or tumoroids, the medium was replaced with a feeding medium containing Gemcitabine at the desired concentrations, and tumoroids were subsequently exposed to ionizing radiation using an Xtrail XENX XSTRAHL Irradiator delivering a dose rate of approximately $0.75 \mathrm{~Gy} /$ minute. After 3 days, the culture medium was replaced with a standard medium. Before reading, cells in monolayers were incubated 30 minutes with Readyprobes blue (Invitrogen) for nuclei staining for live-cell imaging. High-content images were acquired with the Cytation 3 automated microscope (Biotek) at $4 \times$ magnification, and analysis was performed using the Analysis software (Biotek). All experiments were completed at least in triplicate. 


\subsection{Immunofluorescence}

Cells were seeded on slides and incubated for $48 \mathrm{~h}$ at $37^{\circ} \mathrm{C}, 5 \% \mathrm{CO}_{2}$. After two PBS washes, cells were fixed for 15 min with 4\% paraformaldehyde, followed by PBS wash before permeabilization with PBS $1 \times-0.1 \%$ NP40 for $15 \mathrm{~min}$. Cells were then incubated with the appropriate primary antibody diluted in 1\% BSA-0.5\% Tween 20 for $1 \mathrm{~h}$ and then with the secondary antibody and with DAPI (4', 6'diamidino-2-phenylindole). Finally, two washes were performed before mounting the slides in the mounting medium (Dako Fluorescent Mounting Medium). The different antibodies used were mouse anti-cytokeratin 18 (CK-18) monoclonal antibody (sc-32722, Santa Cruz), rabbit anti-Protein C (SP-C) rabbit polyclonal antibody (Ab 40879, Abcam) and mouse smooth muscle anti-actin (alpha-SMA) monoclonal antibody (A5228, Sigma). The secondary antibodies coupin were Alexa-fluor 488 goat anti-mouse (Life Technologies), the Alexa-fluor 546 anti-rabbit mor kev (Life Technologies) and Alexafluor 546 goat anti-mouse (Life Technologies). After mountino i he s des, slides were visualized with a Nikon Eclipse 2000-C1 confocal microscope and filters charanderistics of the fluorochrome used, and the $20 \times$ and $60 \times$ immersion objec $\because$ es. The images were then converted to Tiff format and analyzed using the Nikon EZ-C1 micr ss sne software.

\subsection{Statistics}

Results are presented with a standard teviation of the mean in all studies. Statistical differences between each subtype of cancer were in $:$ 'rzed using a Student's t-test or ANOVA, as indicated, with GraphPad Prism 4 software. A p-va uc 0.05 or less is considered significant. All experiments are compared to a control condition ? ells unly treated with the vehicle) to allow statistical comparisons. 


\section{Results}

\subsection{Patient-Lung Derived Tumoroid (PLDT) lines characteristics}

Recently, we have shown that PLDTs can be readily established from the majority of clinical tumor-containing NSCLC specimens tested [10]. Starting from January 2015 to February 2016, we collected a biopsy sample from 12 different lung cancer patients. The clinical characteristics of these patients are presented in Table 1. Known oncogenic mutations were sought in the genes EGFR, KRAS, ERBB2, ALK, ROS1, and BRAF, and mutations were detected for seven of the twelve patients (58.3\%) (Table 1). Among these 7 samples, two had an EGFR mutation (CLC3 and CLC7) and five a KRAS mutation (CLC1, 6, 8, 9, 10). The histology included eleven adenoc " cinoma and one squamous cell carcinoma (Table 1).

\subsection{Human lung tumor cells isolation from biopsies by explant c."I-cı Iture.}

The primary explant technique is particularly us ful t $r$ disaggregation of small quantities of tissues. The tissue in basal salt solution was finely chor ped (. igure $1 \mathrm{~A}, \mathrm{a})$, and washed by settlings. The basal salt solution was then removed. The ti. - ue pieces were spread into 6-well plates and supplemented with two different types of $r_{i}$ ec um. The explants were attached to the bottom of the plate (Figure $1 \mathrm{~A}, \mathrm{~b}$ ) and observed perioa. - 7 lly. After the addition of the appropriate medium, incubation was carried out for 3-8 days. $\left.W_{1},\right\urcorner n$ the outgrowth of tumor cells was observed (Figure 1A, c), cells were transferred into a fresh nel/ $d$ sh for subculture (Figure 1B). This method requires serial sub-culturing to obtain primary luric tumor cell lines (Figure 1B). Explants of human bronchial tumor biopsies have been cultured in wo tifferent mediums: Medium A and Medium B (see Materials and methods) (Figure 1C-E). We hav assessed the success rate of the establishment of patient-derived cell lines obtained witi, ho. $h \mathrm{r}$.ediums (Figure $1 \mathrm{C}$ ). We then compared and evaluated the yield and the presence of epithelial $c$.lls for each medium. We observed a better yield with medium B (Figure 1D). The outgrowth of epithelial cells was observed within 6 to 8 days (Figure 1E). Taken together, these results show that human lung tumor cells grown from our explant cell culture method from patients' biopsies in medium B is suitable for developing primary lung tumor cell lines. 
Figure 1

A

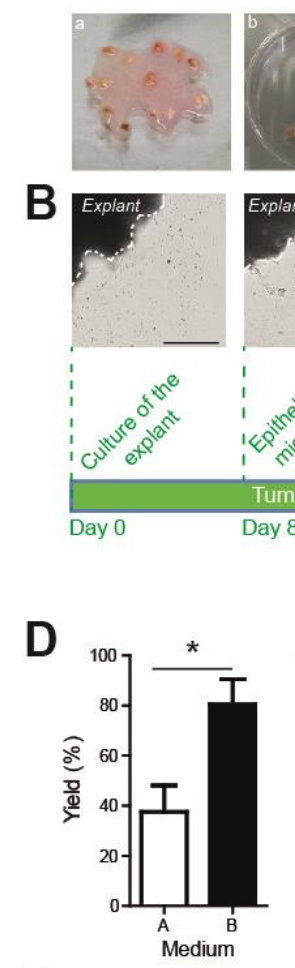

$\mathbf{F}$

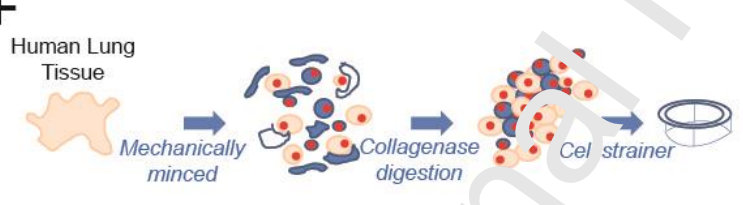

G

\begin{tabular}{|c|c|c|c|}
\hline Biopsy & $\begin{array}{l}\text { Collagenase } \\
(\mathrm{U} / \mathrm{ml})\end{array}$ & $\begin{array}{l}\text { tig. tion } \\
\text { Time? }\end{array}$ & Results \\
\hline CLC5 & $\begin{array}{c}1500 \mathrm{U}^{\prime} \\
50 \mathrm{U}\end{array}$ & $\begin{array}{l}2 . \\
i h\end{array}$ & - \\
\hline CLC6 & $\begin{array}{l}15^{\prime} \mathrm{u} \\
15\end{array}$ & $\begin{array}{c}30 \mathrm{~min} \\
1 \mathrm{~h}\end{array}$ & $\begin{array}{c}+ \\
+++\end{array}$ \\
\hline CLC7 & $70 \mathrm{~b}$ & $1 \mathrm{~h}$ & - \\
\hline CLC8 & $1 / U$ & $2 \mathrm{~h}$ & +++ \\
\hline CLC9 & $1708 \mathrm{~J}$ & $2 \mathrm{~h}$ & + \\
\hline CLC10 & $1, \cup 8 \mathrm{U}$ & $2 \mathrm{~h}$ & - \\
\hline CLC11 & $\begin{array}{l}1500 \mathrm{U} \\
1708 \mathrm{U}\end{array}$ & $\begin{array}{l}\text { 1h } \\
1 \mathrm{~h}\end{array}$ & - \\
\hline CLC12 & $\begin{array}{c}1500 \mathrm{U} \\
1000 \mathrm{U} \\
500 \mathrm{U}\end{array}$ & $\begin{array}{l}2 \mathrm{~h} \\
2 \mathrm{~h} \\
2 \mathrm{~h}\end{array}$ & $\begin{array}{l}++ \\
+ \\
+\end{array}$ \\
\hline
\end{tabular}

$\mathrm{E}$

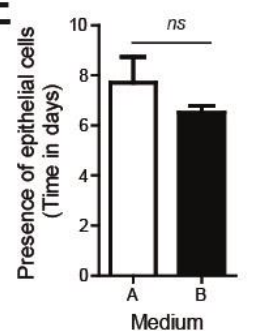

C

\begin{tabular}{|ccc|}
\hline Biopsy & $\begin{array}{c}\text { Explants } \\
\text { Growth Medium }\end{array}$ & Yield (\%) \\
\hline \multirow{2}{*}{ CLC1 } & A & 28.6 \\
& B & 0 \\
\hline \multirow{2}{*}{ CLC2 } & A & 5.9 \\
& B & 66.6 \\
\hline \multirow{2}{*}{ CLC3 } & A & 75 \\
& B & 100 \\
\hline \multirow{2}{*}{ CLC4 } & A & 0 \\
\hline CLC5 & B & 50 \\
\hline CLC6 & A & 40 \\
\hline CLC7 & A & 50 \\
\hline Cl $C 8$ & A & 94.5 \\
\hline 는 9 & B & 63.3 \\
\hline
\end{tabular}

C
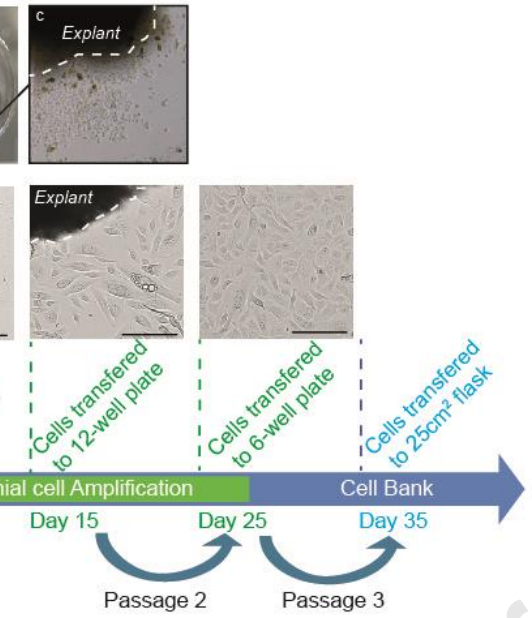

Passage 2

Passage 3
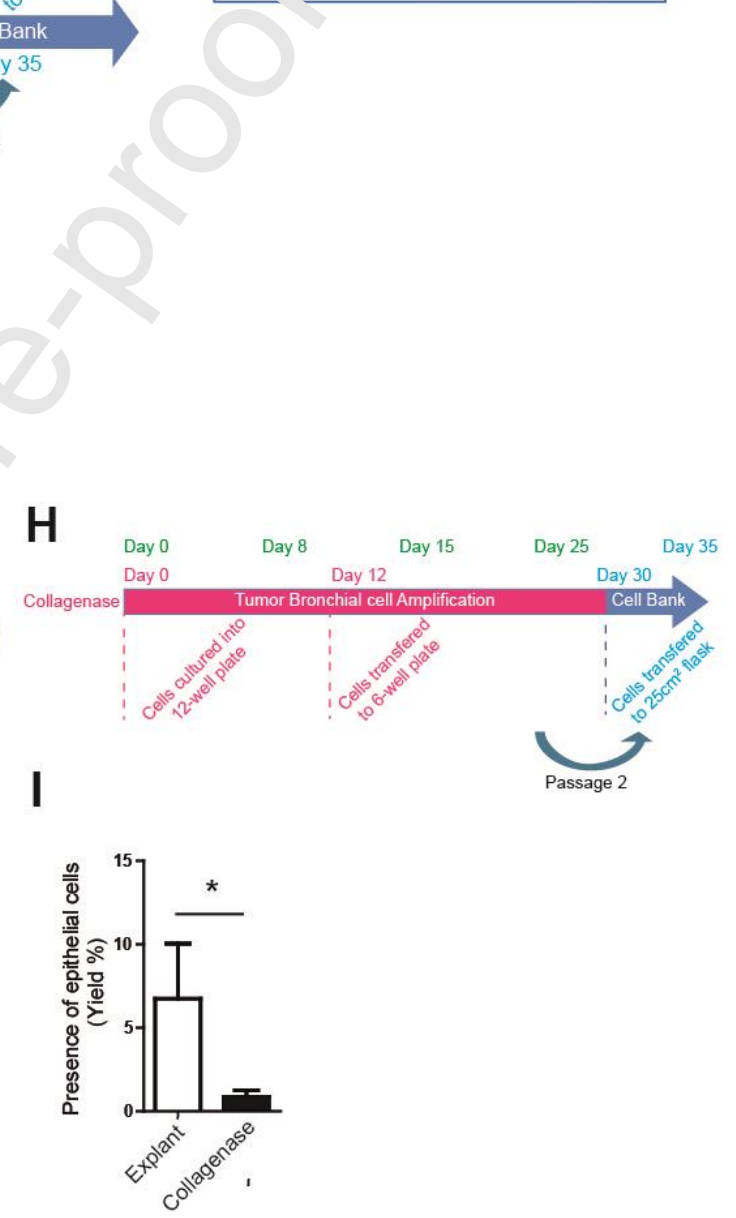

Figure 1 Human bronchial tissue segments and freshly isolated lung cancer epithelial cells. A, Representative picture of human bronchial tissue segments $-\sim 1-2 \mathrm{~cm}$ long and $<1 \mathrm{~cm}$ diameter- (a) used for primary cultures of human lung epithelial cells. (b-c) Brightfield pictures representative of the outgrowth of the explant. B, Human lung epithelial cells grown from explants on tissue culture plates. Note the ring of cells of about 1-2 cm which becomes visible to the naked eye after 3-4 weeks. Images represent the edge of explant tissue and epithelial cells as they migrate from the explant, Scale bar $=100 \mu \mathrm{m}$. The chronology illustrates the different steps to amplify cells. C, Table recapitulating the conditions assessed, two variables were tested: medium A and/or medium B for 
each cancer lung cell line (CLC). D, The bar graph shows the yield in percentage of cells (mean \pm s.e.m) obtained in Medium A as compared to Medium B from three independent biological replicates. ${ }^{*} p<0.05$ (Student's t-test). The yield in percentage of cells obtained with the explant was than calculated for each condition. E, Time in days to obtain primary lung cancer epithelial cells in their respective medium A vs B (mean \pm s.e.m); from three independent biological replicates, n.s., non-significant. $\mathbf{F}$, Schematic representation of the different steps to dissociate human lung tissue from biopsy with collagenase. G, Table recapitulating the conditions assessed, two variables were tested: the concentration of collagenase and the duration of collagenase treatment. ( - ) no cells were growing, $(+)$ some cells were growing, $(++)$ few cells were growing to further expand, and ( $+++)$ a sufficient amount of cells were growing to further expand. $\mathbf{H}$, The chronology illustrates the different steps required to expand cells either with the collagenase method (Pink). I, Yield in percentage of cells obtained with the explant as compared to collagenase (mean \pm s.e.m from three independent biological replicates). ${ }^{*} p<0.05$ (Student's t-test). 


\subsection{Human lung tumor cells isolation from biopsies by enzymatic digestion.}

Enzymatic dissociation is a commonly used practice to digest minced tissue into a single-cell suspension due to proper digestion of tissue and preservation of cell viability and integrity. Enzymatic disaggregation can be carried out by using trypsin, collagenase, or some other enzymes. Since numerous studies have shown that type I collagenase is more effective than other enzymes for dissociation of lung tissue [13], we have used type I collagenase for biopsy dissociation. The procedure to isolate human tumor bronchial cells from biopsies with type I collagenase is outlined in Figure 1F. We have assessed several concentrations and incubation times of type I collagenase (Figure 1G). Our results showed that the best efficiency was obtained with a concentration of 1,500 U of type I collagenase and a time of incubation of 2 hours. Once the ce:- are attached to the 12-well plate and start to divide to reach about $90 \%$ of confluence, cells $\mathrm{a}_{1}>\mathrm{SI}^{\prime} \mathrm{J}$-cultured sequentially into 6well plates and finally in flasks. Although these two methods $r$ resf nted in Figure $1 B$ and $1 \mathrm{H}$, yielded human lung epithelial tumor cells, the explants of human the greatest number of human lung epithelial tumor cells $w^{*} \cdot 1 ., 1 n$ the shortest time (Figure 11). 


\subsection{Morphological characteristics of purified human lung tumor cells.}

Structural characterization of human lung tumor cells showed the characteristic morphology of epithelial cells, such as an adherent monolayer, a cobblestone-like arrangement and a tightly packed pattern (Figure 1B). These primary human lung tumor epithelial cells obtained from biopsies have been maintained for 5 passages, and no obvious morphological change has been observed. Each cell appeared polygonal and flattened, with a large, round nucleus, typical features of normal epithelial cells (Figure 1B). To further characterize these human lung tumor epithelial cells, the expression of cytokeratin 18 (CK18) (an epithelial cell marker) [14, 15] (Figure 2A) and surfactant protein-C (SP-C) (a specific lung cell marker) [16] (Figure 2B) were analyzed at the 2nd passage for the phenotype of Cancer Lung Cells (CLC) from 4 different biopsies (L: 56, CLC1, CLC8, CLC7). The expression of the epithelial cell marker CK18 was examined by ir, mu lofluorescence, indicating the epithelial character of these cells (Figure 2A). Moreover, imm ' nof Jorescence staining showed that SP-C was expressed by all cells, for each patient, indicatir - the lung origin of these cells (Figure 2B). Taken together, these immunofluorescence results show "th cells are positive both for epithelial and lung markers (Figure $2 \mathrm{~A}$ and $\mathrm{B}$ ). Since one of th $=$ ( ancer Lung cell line (CLC5) was expending very fast, we decided to further exploit this cell line. First, we validated by immunofluorescence these markers (CK18 and SP-C). CLC5 cells showt $U$ iform positive immunofluorescence signals for CK18 (Figure 2C) and SP-C (Figure 2D). In coi. ${ }^{+}$rast, immunofluorescence with a specific antibody against fibroblasts cell type did not show any ; 10 : atıon of contamination of cultures by fibroblasts ( $\alpha$-SMA) (Figure 2E), and CLC5 are also neg $\wedge_{1}:^{\circ}$ ior E-cadherin (Figure 2F). In NSCLC, several studies have reported a reduction of E-cadh - in curing malignant transformation [17]. Taken together, these results demonstrate that we have isolated human lung tumor cells from patient biopsies using the explant cell culture metho 
Figure 2

A
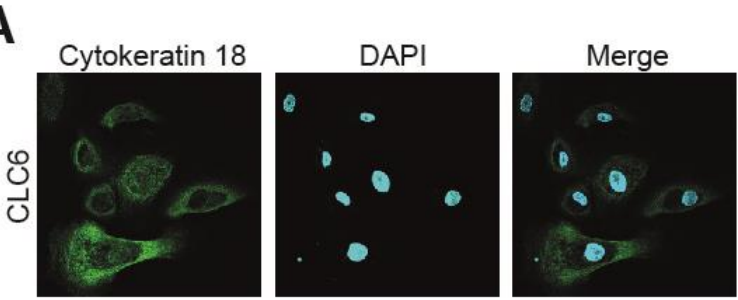

B
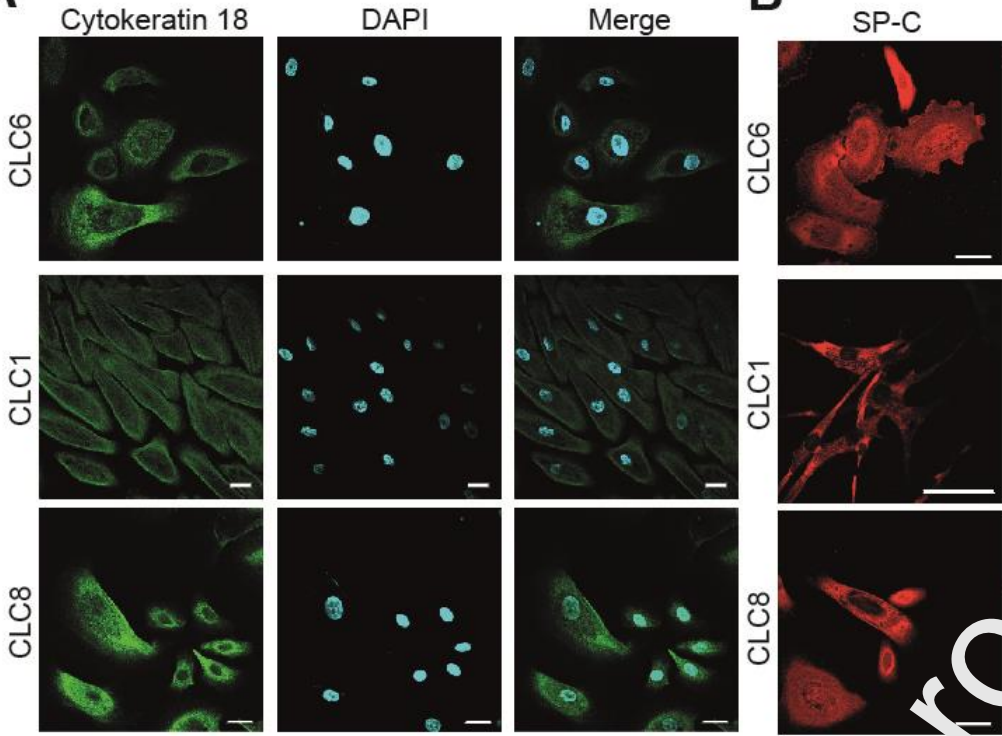

DAPI
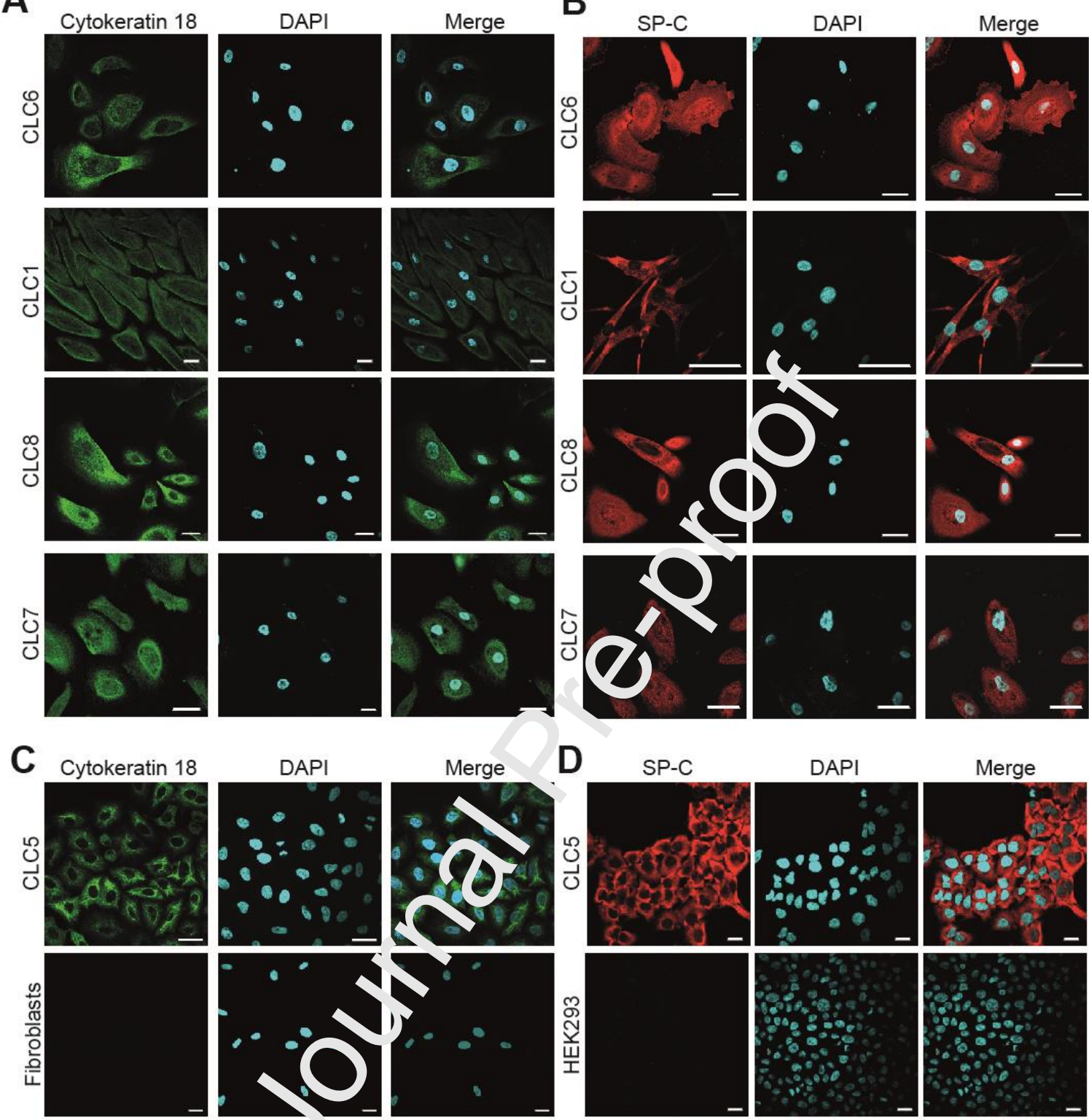

D SP-C
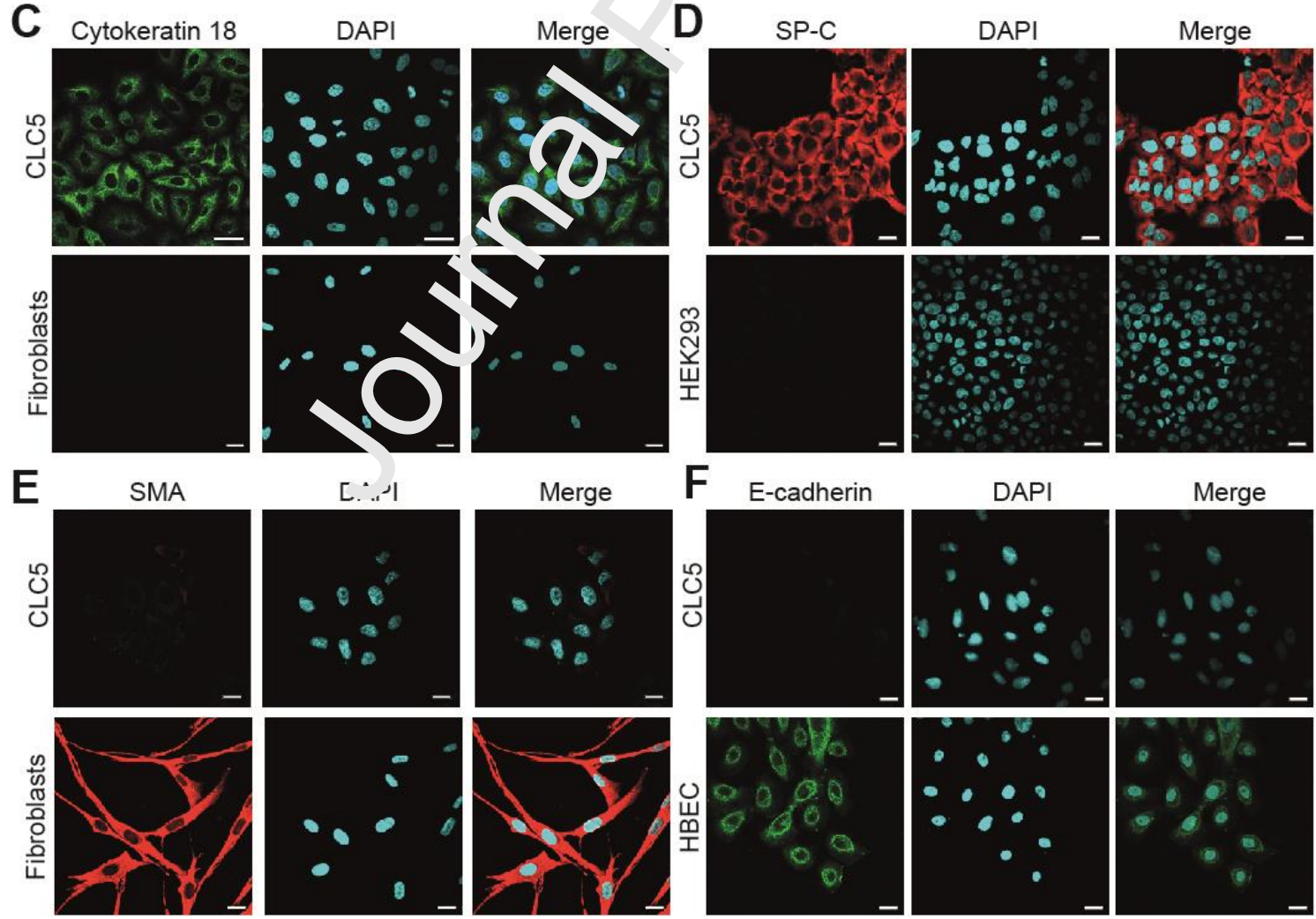

Figure 2: Immunostaining of sub-cultured lung epithelial cells. A-D, Primary cells from patients were seeded on a coverslip and fixed with $4 \%$ paraformaldehyde. Cells were stained with cytokeratin 18 (A and $\mathbf{C}$ ) or surfactant protein C (SP-C) (B and D) and counterstained with DAPI for nuclei. C-F, CLC5 
cells stained positive for cytokeratin 18 (C) and SP-C (D). Cultured lung cells did not stain for $\alpha$-SMA $(E)$, indicating no contamination of the primary cultured lung epithelial cells with mesenchymal cells and stained negative for E-cadherin/Alexa Fluor 546 (F). Positive control for $\alpha$-SMA-cy3 is shown on fibroblasts (E). Positive control for E-cadherin is shown on HBEC epithelial cells (F). Scale Bar=100 $\mu \mathrm{m}$. Images were acquired with the confocal microscope Nikon Eclipse 220-C1. 


\subsection{PLDT establishment from patient-derived cell lines}

Previously, we have described the growth of cancer human bronchial epithelial cells in 3D basement membrane culture with Matrigel $[10,11]$. By comparison between 3D architecture in normal and malignant cell lines, we were able to distinguish normal and malignant human bronchial cells [10, 11]. Our next objective was to compare the drug response in our two different culture systems (2D vs 3D) using the same 2D and 3D methods developed and characterized by our group [10]. Thus, we first established and monitored the 3D cell culture growth of CLC5 tumoroids and evaluated the size of tumoroids over time (Figure $3 \mathrm{~A}$ ). From day 1 to day 6 , tumoroids were in an exponential growth phase and then reached a plateau at day 7 (Figure 3B). We then measured the size (diameter) and the number of tumoroids (Figure 3C-E) using Leica LasX software (set Materials and methods). We set up 10 classes of tumoroids of diameters ranging from $45 \mu \mathrm{m}$ to $\urcorner 45 \mu \mathrm{m}$ (Figure 3D). 


\section{Figure 3}

A
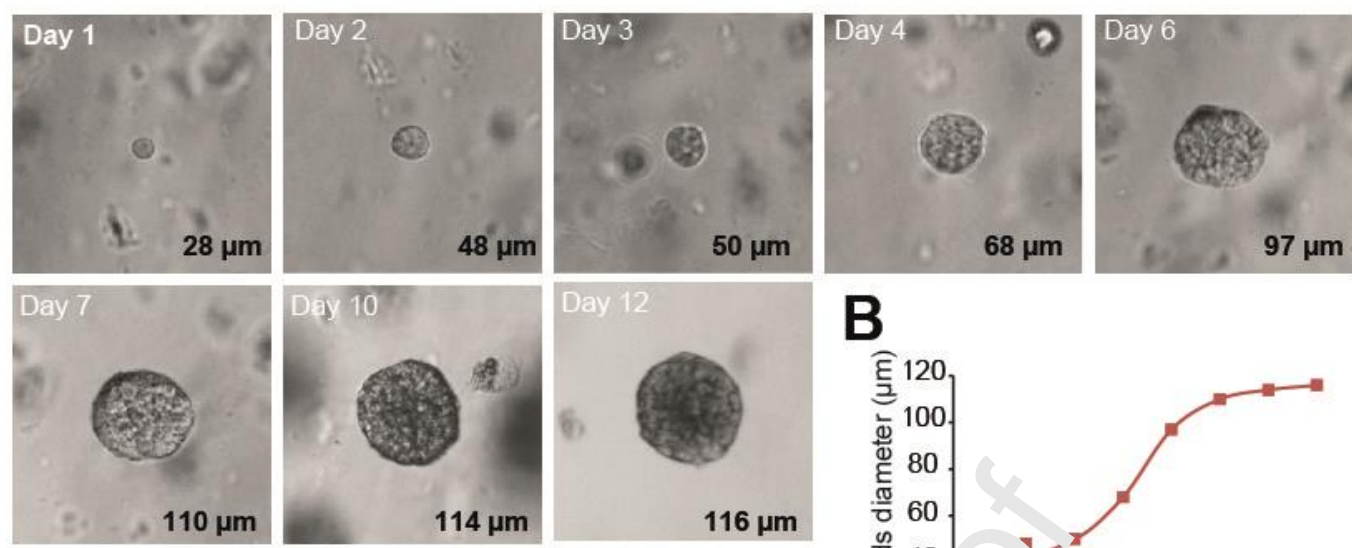

\section{B}

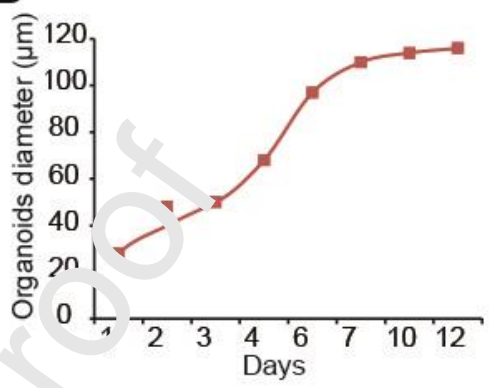

C
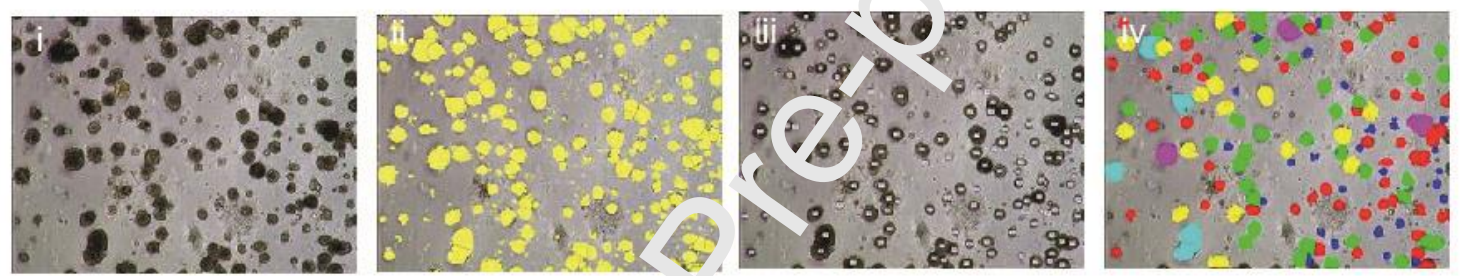

D
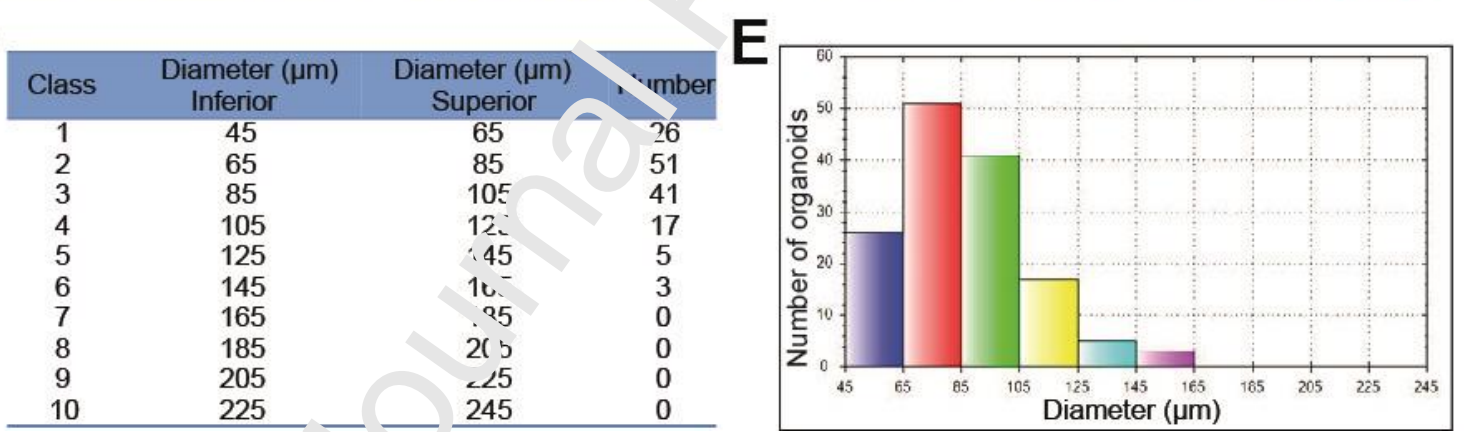

Figure 3: Tumoroids an -1 sis setup. A, Representative field of a tumoroid grown in 3D culture acquired by phase-contrast microscopy (Leica) at objective 5×. B, Analysis of the diameter of tumoroids followed every day until day 12. C-E, A binary treatment was applied to select the tumoroids to be analyzed (i-iv). The accounting software of the total tumoroids by classes (D) previously predefined $(\mathrm{E})$ to measure the tumoroids according to their diameter. 
3.6 Drug sensitivity of 2D cultures as compared to 3D tumoroids (PLDTs).

Next, we examine the drug sensitivity of $2 \mathrm{D}$ cultures from human lung tumor cells relative to their respective 3D PLDTs cultures. Figure 4A describes the strategy used to investigate differences between monolayer and PLDTs cultured tumor lines, obtained from lung cancer patient biopsies. To determine differences in drug sensitivity between cells cultured in 2D and cultured in a 3D matrix (PLDTs), we assessed the impact of chemotherapeutic drug treatments on cell viability. CLC5 cells were cultured in 2D monolayer and treated for 3 or 5 days with a dose ranging from 0 to $100 \mu \mathrm{M}$ with Pemetrexed, Paclitaxel, Docetaxel, or Gemcitabine. Cell viability was then assessed upon exposure to different concentrations of the chemotherapeutic drugs for 3 and 5 days. As shown in Figure 4, the cell viability of CLC5 cells was reduced for each drug te -ted (Figure 4B-F) in a dosedependent manner, with a remarkably strong effect for Gemcitak ne rigure 4F). Since Gemcitabine is the drug which has the best efficacy on the $2 \mathrm{D}$ cell viability 'Figı re $4 \mathrm{~F}$ ), we performed a soft agar colony formation assay to compare the effects of this ag ..+ $c^{-}$the ability of treated cells to divide and form colonies (Figure 4G). Cells treated with Gemcita'-:, ie had significantly less transformation than control cells $(P<0.0001$, Fig. $4 \mathrm{H})$. These res It $^{\text {t }}$ demonstrated that Gemcitabine treatment effectively inhibited cell transformation at a dosc simıar to the one observed in the 2D cell viability assay. 
A

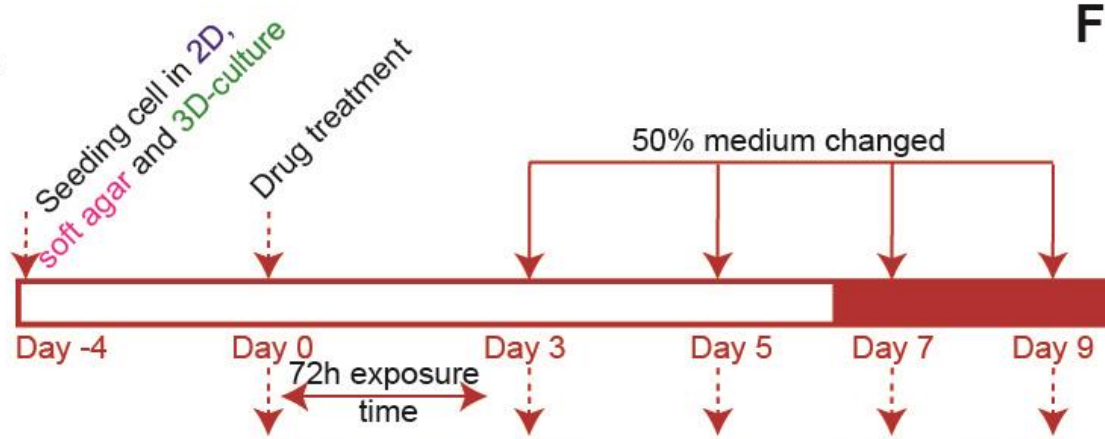

Figure 4

monolayer-cell culture (2D) : Viability Assay (AlamarBlue)

B

Soft-agar assay : Colony Formation units

PLDT-cell culture (3D) : Number and/or size of organoids
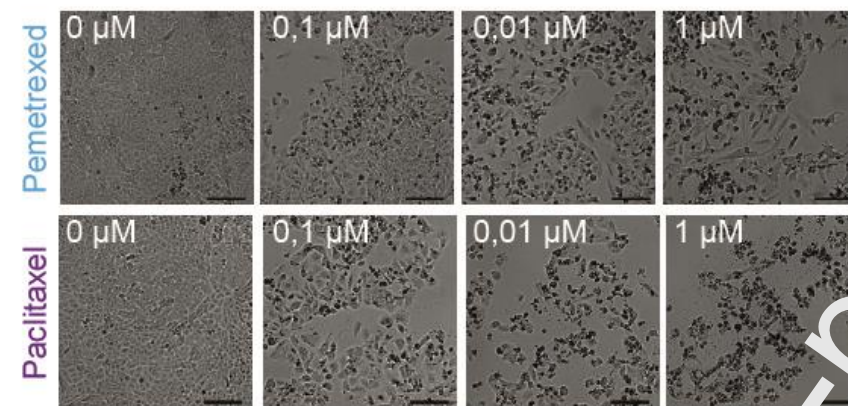

$10 \mu \mathrm{M}<100 \mu \mathrm{M}$
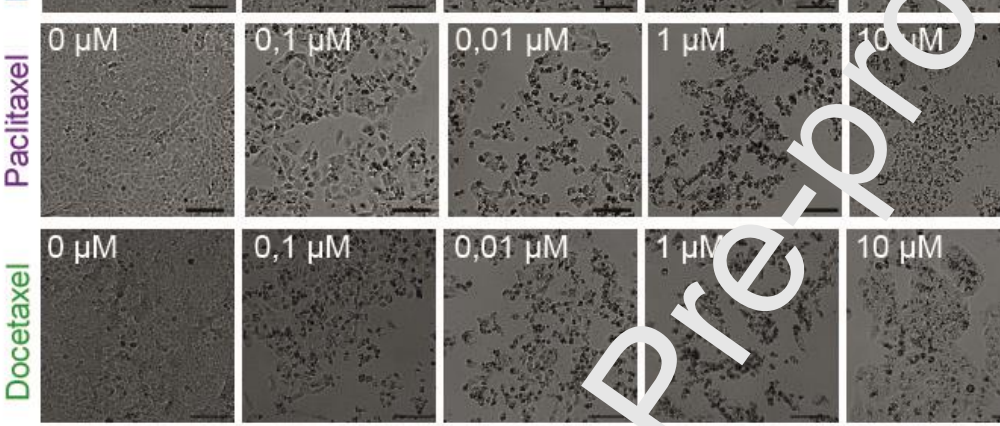

$10 \mu \mathrm{M}$
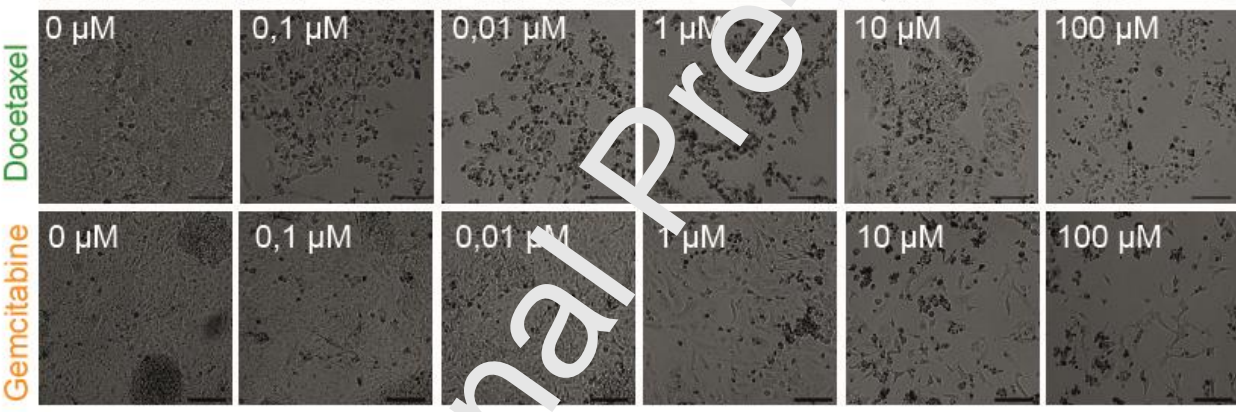

C

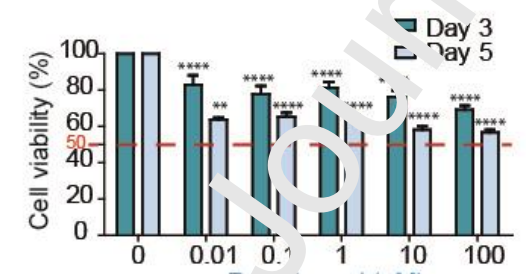

$\mathbf{E}$
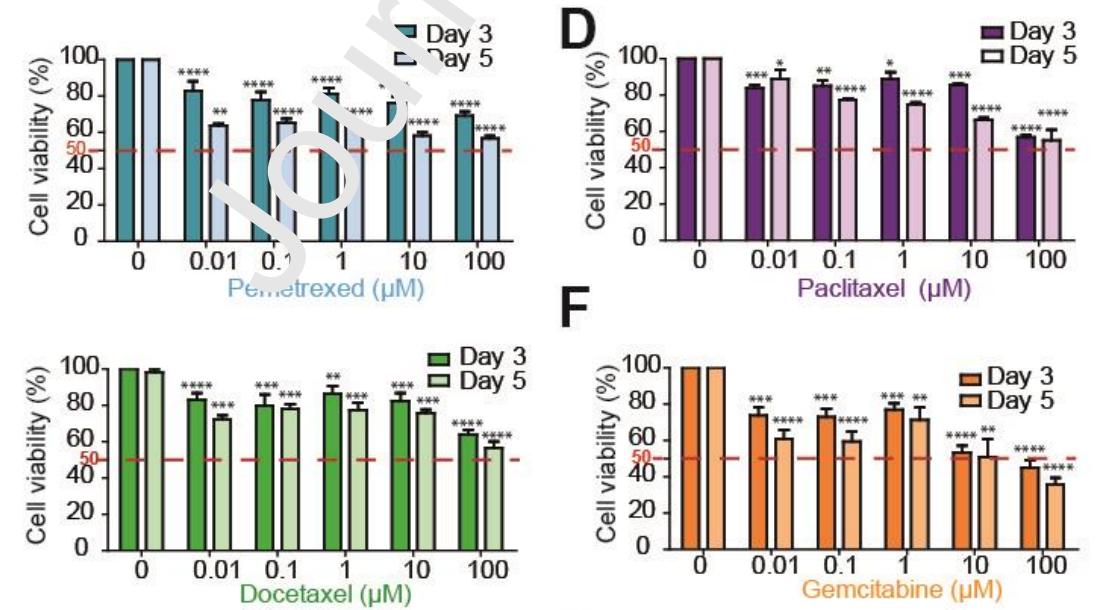

\section{G}

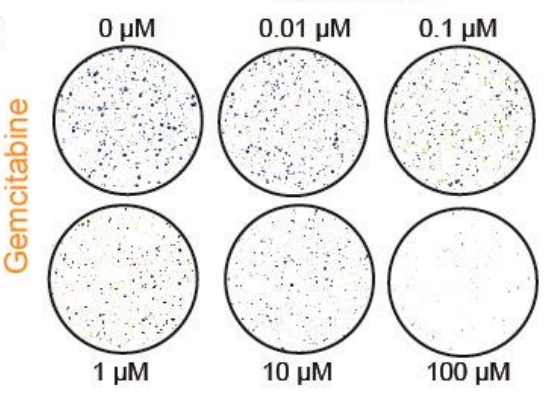

$\mathrm{H}$

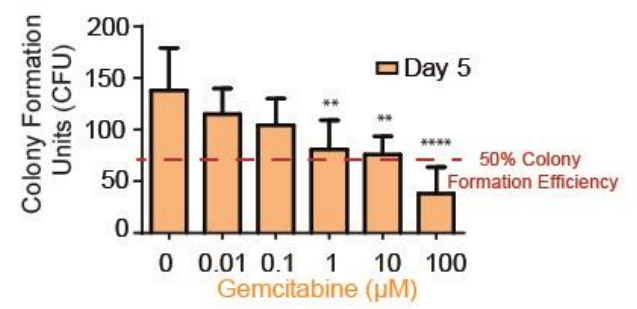


Figure 4: Comparison of the effects of four chemotherapeutic agents on cell viability. A, Timeline of the strategy used to measure the effects of the chemotherapeutic drugs in 2D and in 3D. B-F, Cells are seeded on 96-well plates to measure cell viability on 2D monolayer. Cells are treated with increasing doses ranging from $0 \mu \mathrm{M}$ to $100 \mu \mathrm{M}$ of Docetaxel, Paclitaxel, Gemcitabine, or Pemetrexed, respectively. Representative bright-field phenotype of the cells after drug exposure is shown in $B$. Scale bar $=100 \mu \mathrm{m}$. C-F, Histograms measuring the 2D cell viability (mean \pm s.e.m) following drug treatment from three independent biological replicates. The statistical analysis was performed between no treatment $(0)$ and treated cells. ${ }^{*}$ indicates $p<0.05, * *$ indicates $p<0.001$ and $* * *$ indicates $\mathrm{p}<0.001$ (Student's t-test). $\mathbf{G}$, Soft agar colony formation in the presence of different doses of Gemcitabine. $\mathbf{H}$, The graph shows the number of colonies (mean \pm SEM.) after 3 weeks of three biological replicates. The $p$ values (determined by Student's $t$ test) are relative to control cells $(0 \mu \mathrm{M}) .{ }^{* *} p \leq 0.01, * * * p \leq 0.001$ and ${ }^{* * * *} p \leq 0.0001$. 
Our objective was to compare the drug sensitivity of 2D cultures from human lung tumor cells relative to their respective 3D PLDTs cultures. Our data showed that the anti-cancer Gemcitabine drug had the best efficacy on the 2D cell viability (reduction viability by $50 \%$ (Figure $4 \mathrm{~F}$ )) and a very strongest effect on colony growth assay on soft agar (inhibition cellular transformation by $50 \%$ (Figure $4 \mathrm{H})$ ) on the CLC5 cells, thus, we have investigated the effect of this anti-cancer drug in our 3D model (PLDTs) to compare 2D vs 3D drug responses. Thereby, the impact of Gemcitabine in 3D tumoroid culture was evaluated and compared to the 2D culture (Figure 5). PLDTs from CLC5 were cultured with a dose ranging from 0 to $100 \mu \mathrm{M}$ of Gemcitabine and the number and diameter of PLDTs were measured at 3, 5, and 7 days following treatment (Figure 5A-B). The number of PLDTs was significantly reduced in a dose-dependent manner (Figure 5B). I. contrast, the diameter of PLDTs was not changed whatever the concentration of gemcitabine (dat \& $\mathrm{nc}$ shown). The cell viability rate of the CLC5 cell line in the presence of Gemcitabine was meas art.' on day 3 and day 5 in 3D (Figure 5C) and 2D (Figure 5D) and the ratio of cell viability rates a day 5 was calculated (Figure $5 \mathrm{E}$ ). The $\mathrm{EC}_{50}$ for the CLC5 cells following 3 days of treatment was $5.8 \times 0^{-7} \mathrm{M}$ for $2 \mathrm{D}$ cultures and $1 \times 10^{-5} \mathrm{M}$ for $3 D$ cultures. We then tested the Gemcitabine effect on cell ciath in 2D as compared to 3D culture with drug (Gem) treatment. As shown in Suppleme al al :igure 1, cells were most susceptible to cell death when compared with control cells. Tre $\mathrm{c}$ sse- lependent response of gemcitabine treatments was more effective in 2D than in 3D (Figure $S_{\perp}$; We observed clearly different levels of sensitivity to Gemcitabine, translating into lower rates oi curvival when challenged with different drug amounts in 2D-culture (Figure 5E). Overall, cells gro vn in 3D tumoroids showed higher viability after treatment with increasing doses of gemcitaine compared with cells in 2D monolayer culture. The most straightforward explanation for $\mathrm{Jru}_{c}$ resistance after Gemcitabine treatment in the tumoroids is that the cells inside the tumoroir a: $:$ protected from drug accumulation. Taken together, our findings show that PLDT cultur $\quad(-n)$ ather than monolayer culture (2D) better recapitulate the in vivo response. 
Figure 5

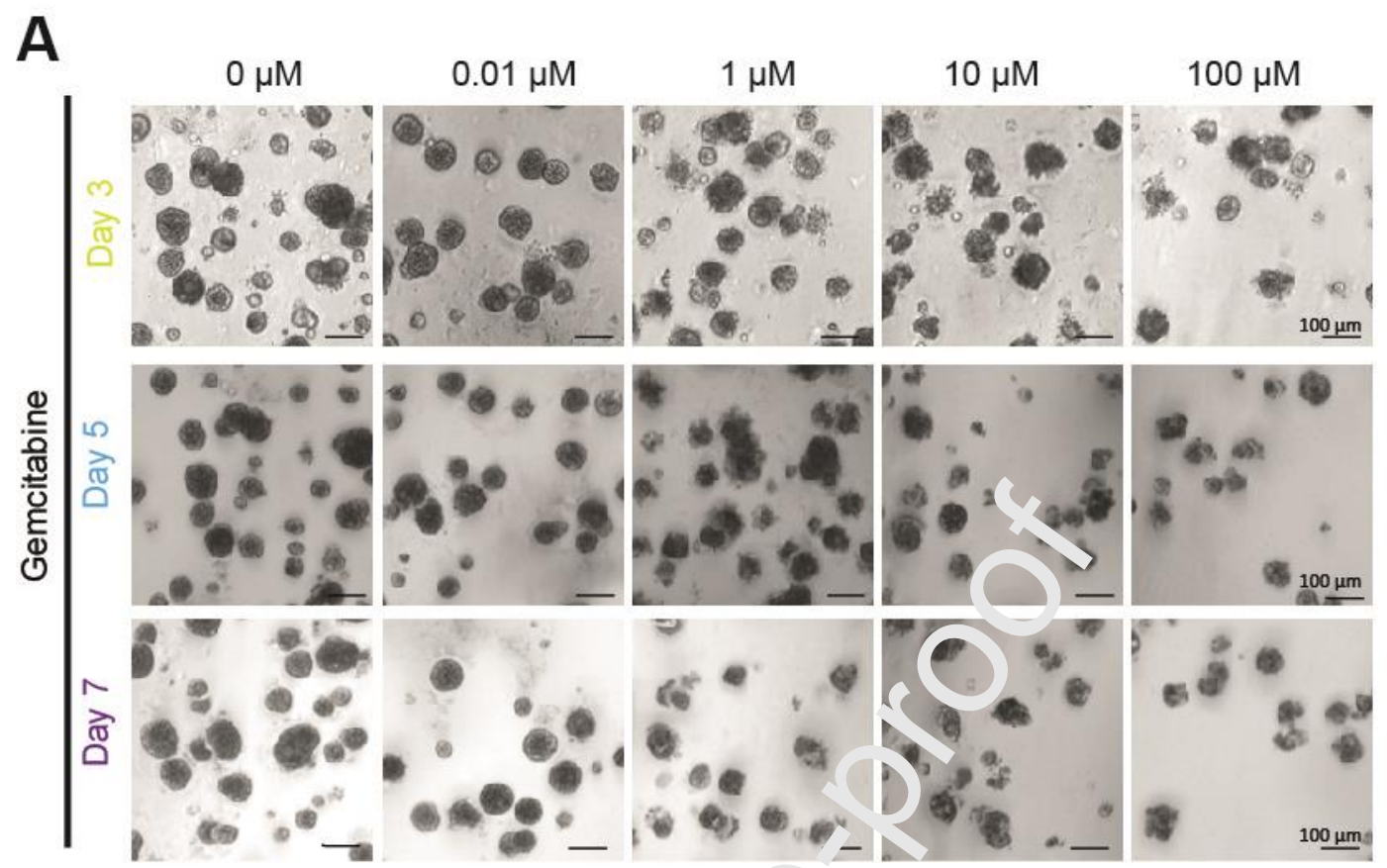

B
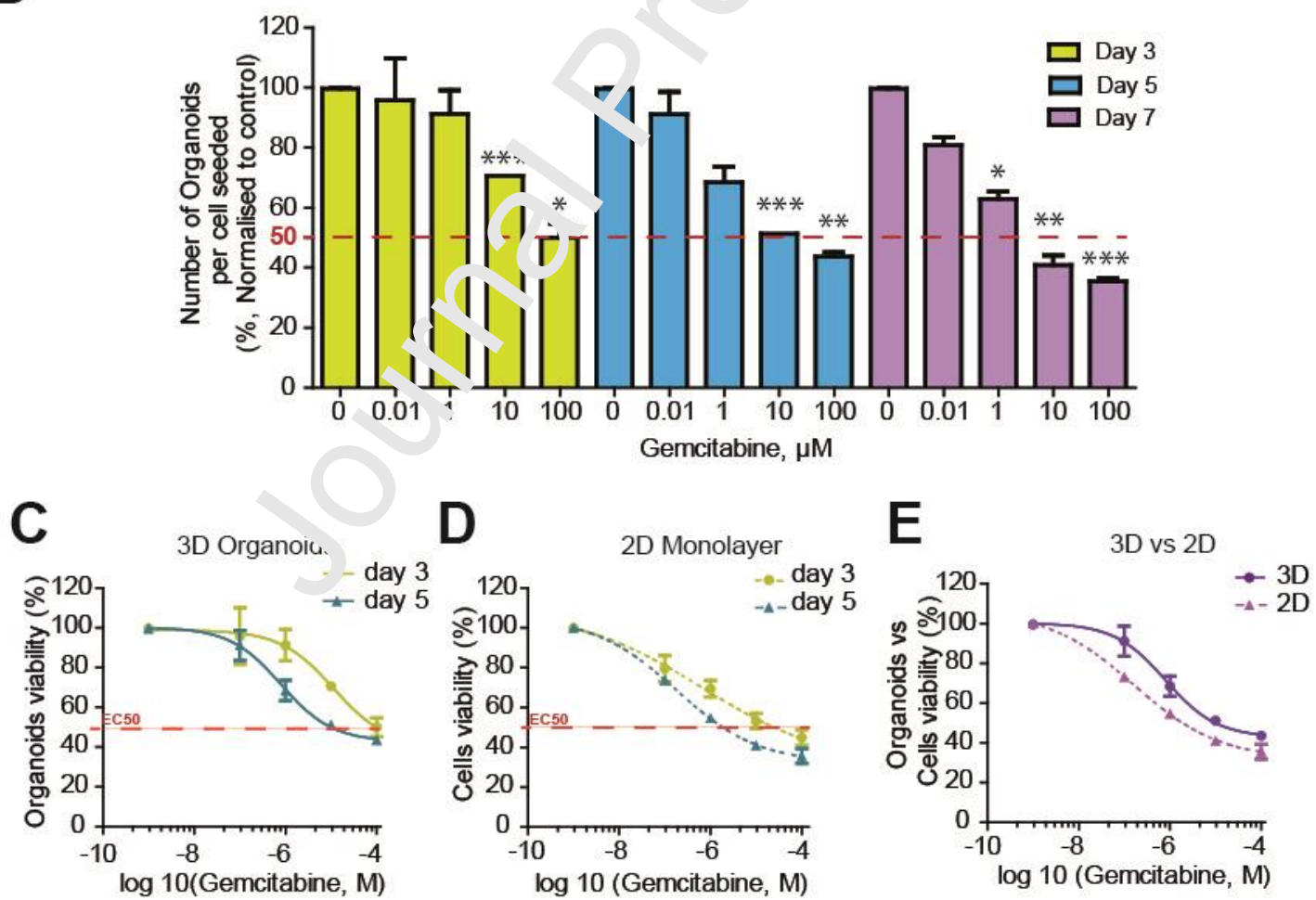

Figure 5: Gemcitabine effect on PLDTs viability after $72 \mathrm{~h}, 120 \mathrm{~h}$ and $168 \mathrm{~h}$ of treatment. A, Tumor epithelial cells were seeded in 3D culture in a 96-well plate. Cells were treated with different doses of Gemcitabine $(0 ; 0.01 ; 1 ; 10$ and $100 \mu \mathrm{M})$, and its effect was measured after 3, 5, and 7 days of treatment. Brightfield pictures were collected using a 10x objective. The scale bar corresponds to $100 \mu \mathrm{m}$. B, Analysis of gemcitabine response on 3D tumor organoids treated for $72 \mathrm{~h}$ with different doses of Gemcitabine or without treatment. Dose-response experiments are presented as a bar 
graph using GraphPad Prism software. Each point is the mean \pm SD of 3 biological replicates. The statistical analysis was performed between no treatment and treated cells. ${ }^{*}$ indicates $p<0.05, * *$ indicates $p<0.001$ and $* * *$ indicates $p<0.001$. C-D, Gemcitabine dose-response curve in 3D tumor organoids and 2D monolayers following 3 days and 5 days of treatment. Dose-response experiments are presented using GraphPad Prism software. Each point is the mean \pm SD of at least 3 biological replicates. E, Comparison of gemcitabine dose-response curve between 3D tumoroids and 2D cell monolayers following 5 days of treatment. Dose-response experiments are presented using GraphPad Prism software. Each point is the mean \pm SD of at least 3 biological replicates. 


\subsection{Identification of differential response of PLDTs to Gemcitabine and/or radiation.}

Chemotherapy and radiation are standard treatments for patients with locally advanced lung cancer. Thus, we sought to analyze the differential response of 2D monolayers as compared to PLDTs treated with chemotherapy and radiation. 2D cell monolayer and tumoroids were grown in feeding media for 96 hours prior to treatment. Baseline brightfield images were acquired prior to treatment with Gemcitabine $(0,1$, and $10 \mu \mathrm{M})$ and radiation (0, 2, or $5 \mathrm{~Gy})$. Cells were exposed to Gemcitabine for $72 \mathrm{~h}$ hours and radiation once. Brightfield imaging was performed again after 3 and 5 days (Figure $6 A, D, G, J)$. Change in diameter of individual tumoroids was measured and compared across samples and treatment conditions as a marker of PLDTs growth response (Figure 6B, E, H, K). A significant variation in the cell viability response to Gemcitabine and radiation : $v \varsigma$ observed across samples for both radiation and the gemcitabine dose tested (Figure $6 \mathrm{C}, \mathrm{F}, \mathrm{I}, \mathrm{L}$ ). ( LC5 were responsive to both Gemcitabine and radiation with increasing concentrations of Gen citabine and increased radiation dose as evidenced by a significant reduction in means tumorc:-1s size (PLDT Mean Growth, Figure 6 B, $E, H, K$ ), and in cell viability both in $2 D$ and in $3 D$ (Figur $61, F, J, L$ ). These results indicate a high effect on cellular viability after treatment with Gem $\because$ - bine combined with 2-Gy and 5-Gy radiation.

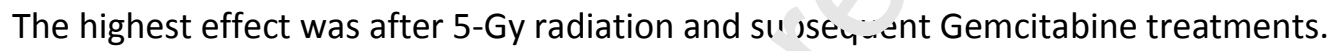


Figure 6

A

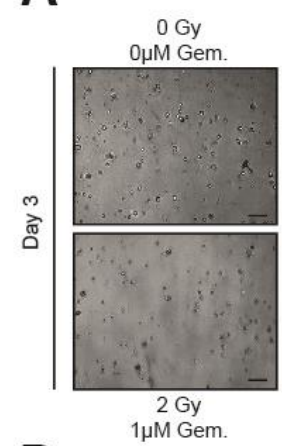

D

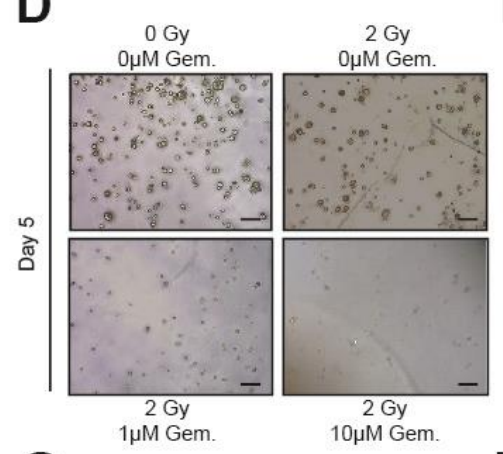

G

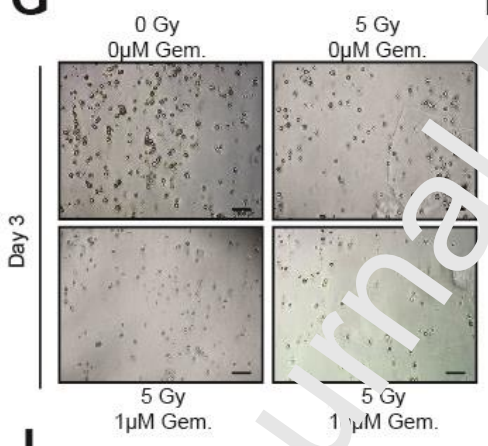

J

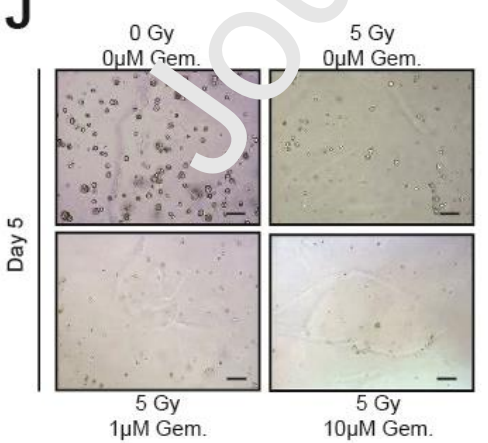

B

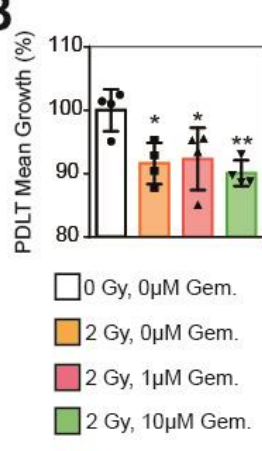

$E_{8}$

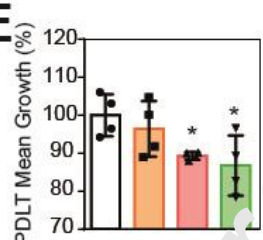

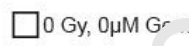
$\square 2 \mathrm{~Gy}, 0 \mu \mathrm{M}$ - $\mathrm{m}$. $\square 2 \mathrm{~Gy}, 1 \mu \mathrm{Mr} \mathrm{em}$. $\square 2$ G. .M Mem.

$\mathbf{H}$

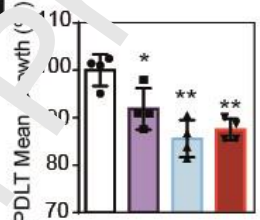

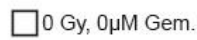

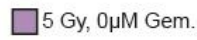
$\square 5 \mathrm{~Gy}, 1 \mu \mathrm{M} \mathrm{Gem}$. 5 Gy, $10 \mu \mathrm{M} \mathrm{Gem}$

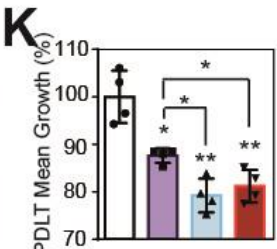

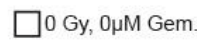
$\square 5$ Gy, $0 \mu \mathrm{M} \mathrm{Gem}$. $\square 5 \mathrm{~Gy}, 1 \mu \mathrm{M} \mathrm{Gem}$. 5 Gy, $10 \mu \mathrm{M} \mathrm{Gem}$
C

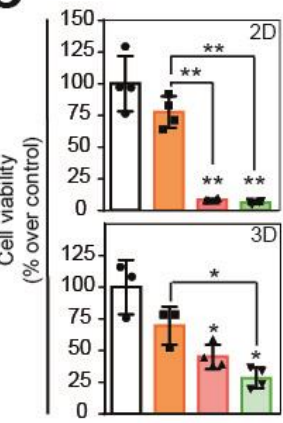

F

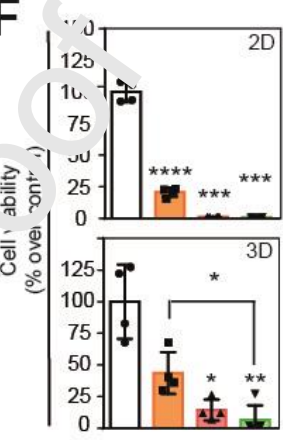

I

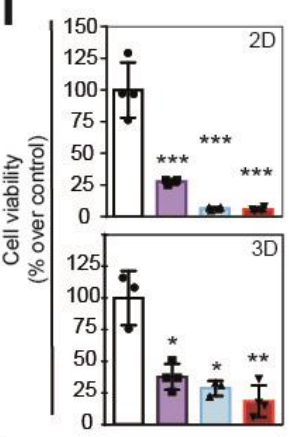

L

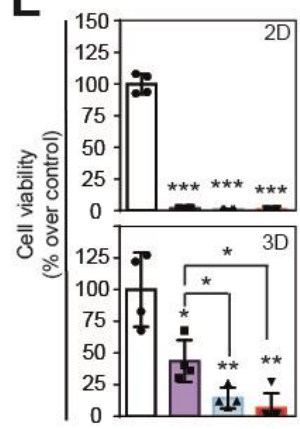

Figure 6: Responses to combined treatment of Gemcitabine and radiation using PLDTs. A,D,G,J, PLDTs were treated with increasing doses of Gemcitabine and/or radiation (0, 2, or $5 \mathrm{~Gy})$ and then PLDTs were observed over 3 and 5 days. Brightfield images are for PLDTs treated with control (vehicle), 1 or $10 \mu \mathrm{M}$ Gemcitabine and 2 or 5 -Gy radiation baseline and 3 or 5 days post-treatment. Scale bar $=100 \mu \mathrm{m}$. B, E, H, K, Mean tumoroids growth (\%) was measured for the different treatment conditions. Growth is defined as a change in tumoroid diameter. C, F, I, L, Analysis of radiation and or 
Gemcitabine responses on cell viability in 2D as compared to 3D tumoroids treated for 3 and 5 days. Cell viability is presented as a bar graph using GraphPad Prism software. Each point is the mean \pm SEM of at least 4 biological replicates. ${ }^{*} p<0.05,{ }^{* *} p<0.01,{ }^{* *} p<0.001,{ }^{* * *} p<0.0001$ and $* * * * p<0.0001$ (Student's t-test). 


\section{Discussion}

Human cell-based models are required for determining relevant pathways involved in human lung cancer mechanisms and for developing cell-based in vitro screening of new drugs, leading to early evaluation and better success rates. Personalized lung cancer medicine is devoted to tailoring the most appropriate drug to be prescribed to individual patients. To achieve this goal, genomicbased drug response prediction has enabled better decision making in oncology. However, evaluating the functionality of these predictions is difficult because of the lack of representative patient lung tumor models that can recapitulate all the key features of original tumors.

Here, we showed that PLDTs have great potential for prea:-ing clinical responses to drugs and for selecting treatments. This type of culture has been previo sly _ hown to maintain the features of cancers from which they derived, including genetic and .nt. . bo bolic alterations, and also drug responses [12]. In this study, we presented detailed met' ods ror culturing and expand primary human lung tumor epithelial cells from biopsy. We obta ned 'ung cancer explants, freshly collected by biopsy and confirmed by immunofluorescence for 'ne p. asence of specific human lung tumor epithelial cells, and tried to establish lung cancer. II ' nes from twelve patients' tumors (CLC1 to

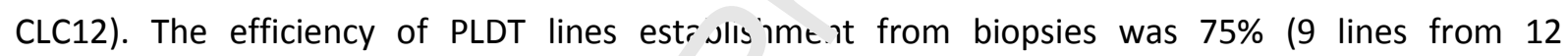
"attempts" from cancer biopsies) and coula , resumably be improved by further optimization of growth conditions. We demonstrated how . xplants of bronchial tumor tissue, cultured in media that promote epithelial cell growth, can provi te a continuous source of human lung tumor epithelial cells.

These human lung tumc celis can be utilized in drug testing systems that more closely resemble cells living in their act : al physiologic environment. Cell-cell and cell-ECM interactions observed during in vivo tu nor vrogression cannot be studied in 2D models, whereas the 3D models are capable of mimicking hese conditions. Consequently, various lung cancer cell lines have been tested in the literature for their ability to grow as tumoroids in 3D culture $[10,18]$. Thus, in this study, we have investigated and showed that $3 \mathrm{D}$ cultures of human lung epithelial tumor cell lines are generally more resistant to chemo- and radio-therapy than their 2D counterparts. Anticancer effects of various chemotherapeutic agents were studied and conventional $2 \mathrm{D}$ and $3 \mathrm{D}$ cell cultures were compared. Chemo-resistance in tumors is mediated by various mechanisms. The classical mechanisms are based on ATP-binding cassette $(A B C)$ transporter proteins, such as $A B C C 5$ (MRP5)[19], which have been reported to contribute to chemo-resistance [20]. High-affinity uptake of gemcitabine is basically mediated by the pyrimidine-preferring nucleoside transporter hCNT1 and also hENT1 which plays a role in drug uptake [21]. Thus we cannot exclude the possibility that 
nucleoside transporters would significantly contribute to gemcitabine cytotoxicity, especially in lung tumor types in which this drug is currently used. This remains to be elucidated.

However, validated $3 \mathrm{D}$ in vitro lung cell models have not been developed for rapid and standardized screening of chemo- and radio-resistance. A combined measure using the change of tumoroid size and number appears to be a robust measure of response for studying chemoresistance mechanisms.

One of the goals of this work was also to gain further experience using PLDTs to predict the effectiveness of chemotherapy and radiation for patients with lung cancer. In the present study, gemcitabine and irradiation treatment were more effective in $\mathrm{m}^{\circ}$-olayers as compared to PLDT. Combination treatment led to both a significant decrease in cell vi bilı $/$ and PLDT growth.

We found that 3D tumoroids are substantially more, osis ant to radiation than monolayer cultures, with a dose modification factor of 3 for 2-Gy - - liaiin $^{-1}$ and 25 for 5-Gy radiation. This is probably due to factors characteristic of tumoroids, such $\because$ the presence of hypoxic cells and of a high proportion of non-proliferating cells. As hypox $d$, thought to be a major factor responsible for the radioresistance of tumor cells [22], it is + issible that hypoxic regions in tumoroids might influence the effects of radiation. However, in c sme studies, the correlation between radioresistance and hypoxia was not evident $[23,24]$, si ogesting that other factors such as cell-cell contact and the importance of the fraction of non-pro'it , sting cells might play a more important role in radiation outcome. This remains elusive.

In addition to its cyt rto, : effect, Gemcitabine is a potent radiosensitizer $[25,26]$. Gemcitabine is activated bv 1. 're eoside kinases into two compounds, gemcitabine diphosphate (dFdCDP) and gemcitai ne rin',osphate (dFdCTP) [27]. Gemcitabine diphosphate (dFdCDP) has been shown to inhibit ribonurle tide reductase, which is responsible for catalyzing the reactions that generate the deoxynucleotides required for DNA synthesis and repair; whereas gemcitabine triphosphate competes with dCTP for incorporation into DNA during replication, which results in a termination of chain elongation [27]. The mechanism of radio-sensitization or radio-enhancement by gemcitabine has been associated with the depletion of the dATP pools, the accumulation of cells in $\mathrm{S}$ phase of the cell cycle, the p53 status, the induction of apoptosis, the increase of DNA double-strand breaks, and the modification of DNA repair pathways [28]. Herein, we showed that gemcitabine can enhance the effects of irradiation in both 2D and 3D tumoroids, while the effect was more pronounced in 2D. Although, a critical limitation remains from this model is the lack of a cancer microenvironment including stromal cells and immune cells, because tumoroids are derived only from human lung epithelial cancer cells. Thus, to investigate the interaction between cancer cells and 
the microenvironment, a co-culture system with immune/stromal cells should be developed in the next future.

In conclusion, we established a PDLTs model that will be a useful platform for drug screening and new clinical trials. Additionally, considering the short length of time from the model establishment to drug testing, our model can be used for predicting patient-specific drug responses as well as broader preclinical studies. Therefore, the ability to predict outcomes in preclinical animal experiments and clinical trials can be better understood using 3D cultures, which is a potentially useful predictive tool in the clinical setting for drug screening in the future. Using PLDTs cultures from surgical patients can be expanded to various fields of drug sensitivity testing, radiosensitivity testing, and novel drug delivery approaches for personal theraneu. is strategies of lung cancer patients. 


\section{Acknowledgements}

We gratefully acknowledge the members from the ARTiSt group for their critical remarks. This work was supported by grants from the "Région Nouvelle-Aquitaine". FD was supported by grants from the "Fondation ARC pour la Recherche sur le Cancer". DF has been supported by the "Agence Nationale de la Recherche (ANR)". TG was supported by the "SIRIC Brio". We would like to acknowledge Marie-Alix Derieppe for help in setting up the radiation experiment. 


\section{References}

[1] J. Yokota, T. Kohno, Molecular footprints of human lung cancer progression, Cancer science, 95 (2004) 197-204.

[2] W.D. Travis, E. Brambilla, P. Van Schil, G.V. Scagliotti, R.M. Huber, J.P. Sculier, J. Vansteenkiste, A.G. Nicholson, Paradigm shifts in lung cancer as defined in the new IASLC/ATS/ERS lung adenocarcinoma classification, The European respiratory journal, 38 (2011) 239-243.

[3] W.D. Travis, Pathology of lung cancer, Clinics in chest medicine, 32 (2011) 669-692.

[4] Y. Sekido, K.M. Fong, J.D. Minna, Molecular genetics of lung cancer, Annual review of medicine, 54 (2003) 73-87.

[5] A. Dutt, K.K. Wong, Mouse models of lung cancer, Clinical cancer research : an official journal of the American Association for Cancer Research, 12 (2006) 4396s-440?s.

[6] L. Hutchinson, R. Kirk, High drug attrition rates--where are we ¿oing wrong?, Nature reviews. Clinical oncology, 8 (2011) 189-190.

[7] W.N. Hait, Anticancer drug development: the grand challenges, Na+ure reviews. Drug discovery, 9 (2010) 253-254.

[8] H.B. van der Worp, D.W. Howells, E.S. Sena, M.J. Porritt, ऽ Re..ell, V. O'Collins, M.R. Macleod, Can animal models of disease reliably inform human studies?, " - - - s, nedicine, 7 (2010) e1000245.

[9] A.C. Rios, H. Clevers, Imaging organoids: a bright futur ahf ad, Nature methods, 2018, pp. 24-26.

[10] D. Fessart, H. Begueret, F. Delom, Three-dimensior $\mathrm{Al} \mathrm{Cu}^{1+}$ ure model to distinguish normal from malignant human bronchial epithelial cells, The Eurc pe in respiratory journal, 42 (2013) 1345-1356.

[11] D. Fessart, C. Domblides, T. Avril, L.A. Erikss sn, 4 Begueret, R. Pineau, C. Malrieux, N. DugotSenant, C. Lucchesi, E. Chevet, F. Delom, Sr u tic. of protein disulphide isomerase AGR2 confers tumorigenic properties, eLife, 5 (2016).

[12] M. Kim, H. Mun, C.O. Sung, E.J. Cho, H.J. ^ गn, S.M. Chun, D.J. Jung, T.H. Shin, G.S. Jeong, D.K. Kim, E.K. Choi, S.Y. Jeong, A.M. Taylor, S. '‘in, M. Meyerson, S.J. Jang, Patient-derived lung cancer organoids as in vitro cancer models $f, r$.'. 3991.

[13] J.G. Quatromoni, S. Singhal, $\Gamma$ Bhujnagarwala, W.W. Hancock, S.M. Albelda, E. Eruslanov, An optimized disaggregation metho' for ruman lung tumors that preserves the phenotype and function of the immune cells, Journal of tt 'kocyte biology, 97 (2015) 201-209.

[14] T. Makino, M. Yamasakı, 4. Takeno, M. Shirakawa, H. Miyata, S. Takiguchi, K. Nakajima, Y. Fujiwara, T. Nishida, N. I latsı ura, M. Mori, Y. Doki, Cytokeratins 18 and 8 are poor prognostic markers in patients witı qua..nous cell carcinoma of the oesophagus, British journal of cancer, 101 (2009) 1298-1306.

[15] V. Barak, H. Goike, K.W. Panaretakis, R. Einarsson, Clinical utility of cytokeratins as tumor markers, Clinical biochemistry, 37 (2004) 529-540.

[16] C.F. Kim, E.L. Jackson, A.E. Woolfenden, S. Lawrence, I. Babar, S. Vogel, D. Crowley, R.T. Bronson, T. Jacks, Identification of bronchioalveolar stem cells in normal lung and lung cancer, Cell, 121 (2005) 823-835.

[17] N.H. Myong, Reduced expression of E-cadherin in human non-small cell lung carcinoma, Cancer research and treatment : official journal of Korean Cancer Association, 36 (2004) 56-61.

[18] N. Sachs, A. Papaspyropoulos, D.D. Zomer-van Ommen, I. Heo, L. Bottinger, D. Klay, F. Weeber, G. Huelsz-Prince, N. lakobachvili, G.D. Amatngalim, J. de Ligt, A. van Hoeck, N. Proost, M.C. Viveen, A. Lyubimova, L. Teeven, S. Derakhshan, J. Korving, H. Begthel, J.F. Dekkers, K. Kumawat, E. Ramos, M.F. van Oosterhout, G.J. Offerhaus, D.J. Wiener, E.P. Olimpio, K.K. Dijkstra, E.F. Smit, M. van der Linden, S. Jaksani, M. van de Ven, J. Jonkers, A.C. Rios, E.E. Voest, C.H. van Moorsel, C.K. van der Ent, E. Cuppen, A. van Oudenaarden, F.E. Coenjaerts, L. Meyaard, L.J. Bont, P.J. Peters, S.J. Tans, J.S. van Zon, S.F. Boj, R.G. Vries, J.M. Beekman, H. Clevers, Long-term expanding human airway organoids for disease modeling, The EMBO journal, 38 (2019). 
[19] W. Hagmann, R. Jesnowski, J.M. Lohr, Interdependence of gemcitabine treatment, transporter expression, and resistance in human pancreatic carcinoma cells, Neoplasia, 12 (2010) 740-747.

[20] A. Domenichini, A. Adamska, M. Falasca, ABC transporters as cancer drivers: Potential functions in cancer development, Biochimica et biophysica acta. General subjects, 1863 (2019) 52-60.

[21] J. Garcia-Manteiga, M. Molina-Arcas, F.J. Casado, A. Mazo, M. Pastor-Anglada, Nucleoside transporter profiles in human pancreatic cancer cells: role of hCNT1 in 2',2'-difluorodeoxycytidineinduced cytotoxicity, Clinical cancer research : an official journal of the American Association for Cancer Research, 9 (2003) 5000-5008.

[22] R.M. Sutherland, Tumor hypoxia and gene expression--implications for malignant progression and therapy, Acta oncologica, 37 (1998) 567-574.

[23] A. Gorlach, H. Acker, pO2- and pH-gradients in multicellular spheroids and their relationship to cellular metabolism and radiation sensitivity of malignant human tumor cells, Biochimica et biophysica acta, 1227 (1994) 105-112.

[24] F.M. Buffa, C. West, K. Byrne, J.V. Moore, A.E. Nahum, Radiation response and cure rate of human colon adenocarcinoma spheroids of different size: the sisı ificance of hypoxia on tumor control modelling, International journal of radiation oncology, biol sgy, shysics, 49 (2001) 1109-1118.

[25] D.S. Shewach, T.S. Lawrence, Gemcitabine and radiosons.'- ${ }^{-2}$ tion in human tumor cells, Investigational new drugs, 14 (1996) 257-263.

[26] T.S. Lawrence, A. Eisbruch, D.S. Shewach, Gemcitabine neaı lated radiosensitization, Seminars in oncology, 24 (1997) S7-24-S27-28.

[27] P.A. Risbood, C.T. Kane, Jr., M.T. Hossain, S. Vadap. Ili J.K. Chadda, Synthesis of gemcitabine triphosphate (dFdCTP) as a tris(triethylammonium) salt, sioo ¿ janic \& medicinal chemistry letters, 18 (2008) 2957-2958.

[28] B. Pauwels, A.E. Korst, F. Lardon, J.B. Verm irkt., Combined modality therapy of gemcitabine and radiation, The oncologist, 10 (2005) 34-5. 1. 
Table 1 : Patients' characteristics

\begin{tabular}{|c|c|c|c|c|c|c|c|c|c|}
\hline Patients & Gender & Age & Histology & $\begin{array}{l}\text { EGFR } \\
\text { Exons } \\
18-21\end{array}$ & $\begin{array}{c}\text { KRAS } \\
\text { Exon } 2\end{array}$ & $\begin{array}{c}\text { ERBB2 } \\
\text { Exon } 20\end{array}$ & $A L K$ & ROS1 & $\begin{array}{c}\text { BRAF } \\
\text { Exon } 15\end{array}$ \\
\hline CLC1 & $M$ & 74 & Adenocarcinoma & - & p.G12C & - & - & - & - \\
\hline CLC2 & $\mathrm{F}$ & 61 & Adenocarcinoma & - & - & - & - & - & - \\
\hline CLC3 & $\mathrm{F}$ & 64 & Adenocarcinoma & $\begin{array}{l}\text { Exon } 21 \\
\text { p.L858R }\end{array}$ & - & - & - & - & - \\
\hline CLC4 & M & 59 & $\begin{array}{c}\text { Squamous cell } \\
\text { carcinoma }\end{array}$ & - & - & - & - & - & - \\
\hline CLC5 & $M$ & 79 & Adenocarcinoma & - & - & - & - & - & - \\
\hline CLC6 & $\mathrm{F}$ & 58 & Adenocarcinoma & - & p.G12C & - & - & - & - \\
\hline CLC7 & $\mathrm{F}$ & 62 & Adenocarcinoma & $\begin{array}{l}\text { Exon } 20 \\
\text { Exon } 21\end{array}$ & - & - & - & - & - \\
\hline CLC8 & $\mathrm{F}$ & 83 & Adenocarcinoma & - & p.G12V & - & - & - & - \\
\hline CLC9 & $M$ & 45 & Adenocarcinoma & - & p.G12V & . & - & - & - \\
\hline CLC10 & $\mathrm{F}$ & 69 & Adenocarcinoma & - & p.G12' & - & - & - & - \\
\hline CLC11 & M & 63 & Adenocarcinoma & - & - & - & - & - & - \\
\hline CLC12 & $M$ & 66 & Adenocarcinoma & - & - & - & - & - & - \\
\hline
\end{tabular}




\section{Supplemental Figure 1}

A

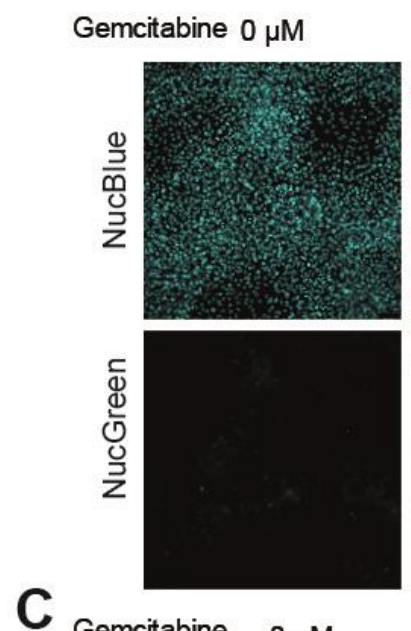

Gemcitabine $0 \mu \mathrm{M}$
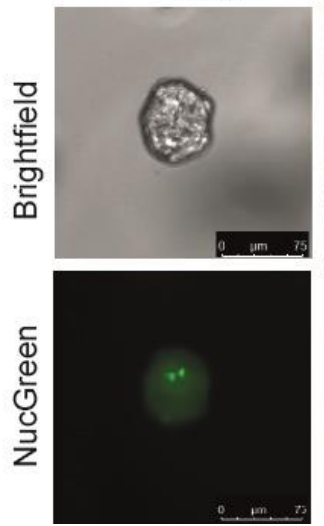

$1 \mu \mathrm{M}$
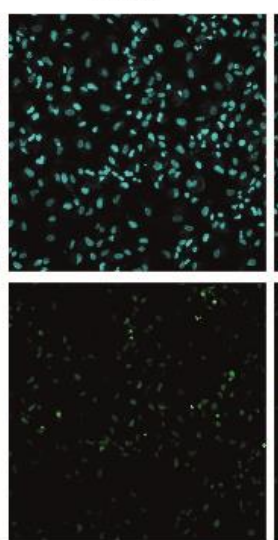

$1 \mu \mathrm{M}$
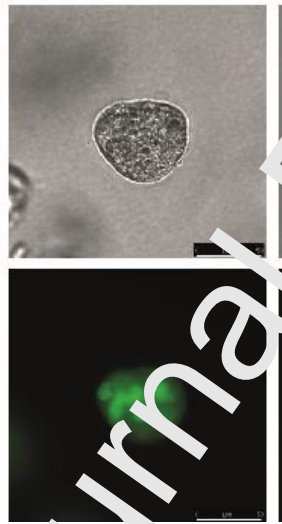

B
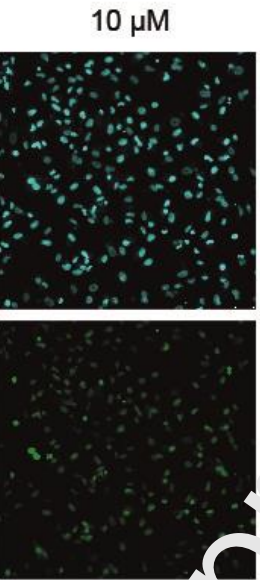

$10 \mu \mathrm{M}$
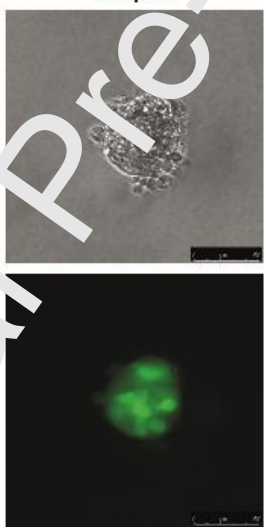

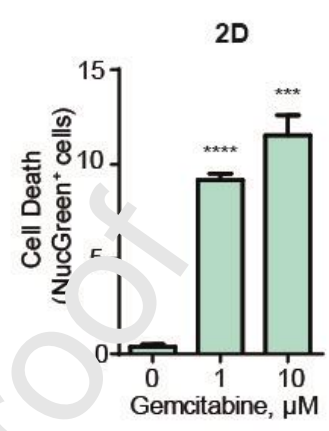

D

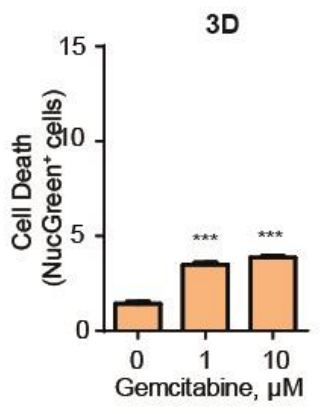

Supplemental Figure 1: Cel death using NucGreen staining of Gemcitabine-treated cells grown as monolayers as compared to tumoroids. A-B, Representative images of 2D monolayer seeded for 4 days and treated with Gemcitabine at different doses in the presence of NucGreen (a marker of dead cells) and Nucblue (nuclei marker) as described in Materials and methods. The images were then acquired at $4 \times$ magnification and fluorescence signals were then quantified to obtain the graph (B). Scale bars indicate $1000 \mu \mathrm{m}$. C-D, Representative images of 3D tumoroids grown for 4 days in Matrigel and treated with Gemcitabine at different doses in the presence of NucGreen (a marker of dead cells) as described in materials and methods. The images were then acquired at $4 \times$ magnification and fluorescence signals were then quantified to obtain graph (D). Scale bars indicate the length in $\mu \mathrm{m}$. Each point is the mean \pm SEM of at least 3 biological replicates. $* * * p<0.0001$ and $* * * * \mathrm{p}<0.0001$ (Student's t-test) relative to control condition (dose 0 ). 


\section{Declaration of interest}

\section{None}

\section{Authors' contributions}

$\mathrm{DF}, \mathrm{IB}, \mathrm{TG}, \mathrm{FS}$ and FD carried out the experiments and related analyses. GS and AMK provided the reagents and critically revised the manuscript. HB provided and analyzed the biopsies. JR critically revised the manuscript. FD, DF designed the study and wrote the manuscript. All authors read and approved the final manuscript. 


\section{Declaration of interests}

$\bigotimes$ The authors declare that they have no known competing financial interests or personal relationships that could have appeared to influence the work reported in this paper.

$\square$ The authors declare the following financial interests/personal relationships which may be considered as potential competing interests: 


\section{CRediT author statement}

DF, IB, TG, FS and FD carried out the experiments and related analyses. GS and AMK provided the reagents and critically revised the manuscript. HB provided and analyzed the biopsies. JR critically revised the manuscript. FD, DF designed the study and wrote the manuscript. All authors read and approved the final manuscript. 


\section{HIGHLIGHTS}

- Establishment of tumoroids derived from lung cancer patients (PLDT) as a platform for drug screening

- PLDT are more resistant to chemotherapeutic drug that cells in 2D culture.

- Gemcitabine can enhance the effects of irradiation in both 2D and 3D tumoroids 